\title{
Stay in School or Start Working? \\ - The Human Capital Investment Decision under Uncertainty and Irreversibility
}

\author{
Natasa Bilkic \\ Thomas Gries \\ Margarethe Pilichowski
}

CESIFO WORKING PAPER No. 2825

CATEGORY 4: LABOUR MARKETS

OCTOBER 2009

Presented at CeSifo Venice Summer Institute, July 2009

An electronic version of the paper may be downloaded

- from the SSRN website:

- from the RePEc website:

- from the CESifo website:

www.SSRN.com

www.RePEc.org

www.CESifo-aroup.ora/wp 


\title{
Stay in School or Start Working? - The Human Capital Investment Decision under Uncertainty and Irreversibility
}

\begin{abstract}
As the time of leaving school determines the level of academic achievement this timing decision is central for the human capital investment decision. Real option theory offers a new perspective of the human capital investment decision under uncertainty and irreversibility. Unlike other approaches we include accumulative schooling costs, and provide a full analytical discussion of all determinants of the decision to terminate education and enter the labor market. Further, as we are able to look at a sequence of formal qualification levels, each characterized by various cost and income profiles we can discuss discontinuities and sheepskin effects within this approach.
\end{abstract}

JEL Code: J24, D81, I20.

Keywords: human capital theory, uncertainty, irreversibility.

Natasa Bilkic

University of Paderborn
Thomas Gries

University of Paderborn

Department of Economics

Warburger Strasse 100

Germany - 33098 Paderborn

thomas.gries@notes.upb.de

Margarethe Pilichowski

University of Paderborn

October 6, 2009 


\section{Introduction}

Education is obtained during a long process of personal maturation and the accumulation of knowledge and abilities. Hence, formal schooling is a learning and investment process that often lasts into one's mid twenties. When a young person makes plans for the future one of the biggest problems is uncertainty. The success of a long education is as uncertain as the process of earning income during a long working life. As time goes on, students repeatedly consider whether to continue their education or enter the labor market. During this sequential process of decision making ${ }^{1}$ each moment's conditions determine the eventual attainment level.

Recent literature shows that real option theory can be applied to take into account uncertain time processes and irreversibility in schooling and human capital accumulation decisions. Hogan and Walker (2007) and Jacobs (2007) pick up these ideas in different ways and show that introducing real option theory can generate new insights in the idea of education as an investment decision in human capital.

The first analysis of investment in human capital under uncertainty was conducted by Levhari and Weiss (1974). Levhari and Weiss model risky future earnings in a two-period approach of human capital formation, concluding that an increase in uncertainty regarding the return on human capital investment decreases the level of investment under given assumptions about risk preferences and risk-return technology. This paper remains a major benchmark. Later, e.g. Eaton and Rosen (1980) extended this framework to analyse tax effects. Dynamic techniques combined with portfolio theory have also gained considerable attention. Williams (1978) examined risky investment in education using a two-period, mean-variance portfolio model. Considering several sources of risk, Williams was able to derive more precise hypotheses about observable variables than Levhari and Weiss (1974). Groot and Oosterbeek (1992) discussed the effects of uncertain future earnings and the probability of unemployment on the duration of schooling. Hanchane, Lioui and Touahri (2006) developed a continuous time dynamic programming model which accounts for several sources of uncertainty with regard to earnings and labor market conditions. They showed that the global effect of uncertainty is negative, except when a sufficiently high risk premium exists.

The application of real options theory to the human capital investment decision is a relatively recent development. Even if Weisbrod (1962) and more formally Comay, Melnik, Pollatschek (1973) suggested the idea more than 30 years ago, a transfer of formal option theory - as established by Dixit and Pindyck (1994) - was suggested only recently. Hogan and Walker (2007) provide an example of this transfer of real option theory to human capital decisions. In their model, at any time a student has the option to leave school to work for wages that reflect the years spent in school. The decision to leave school is irreversible,

${ }^{1}$ See Comay, Melnik and Pollatschek (1973). 
so once the student has finished education they cannot return. They conclude that high returns on education and increasing risk will cause students to stay in school longer. They also analyze how progressive taxation and education subsidies affect schooling decisions and show that progressive taxes tend to reduce educational attainment. Jacobs (2007) uses the real option approach as well. However, unlike Hogan (2007) he uses a discrete time approach and states that the decision to start learning is irreversible. The option value stems from the fact that an individual could wait to enrol and would only do so once the returns are sufficiently large to compensate for the lost option value. The sunk cost of the investment consists of forgone labor earnings and tuition costs.

Looking at recent empirical literature on human capital investments there is evidence that the classical Mincer approach is increasingly unable to sufficiently explain the link between earnings, rates of return and educational attainment. ${ }^{2}$ In line with these findings is the idea of introducing risk and other non-pecuniary elements in the empirical model. ${ }^{3}$ Further, Heckman, Lochner, and Todd (2006) give reasons why option values should be included in the decision, and show how option values invalidate the internal rate of return as an investment choice criterion. "Our analysis points to a need for more empirical studies that incorporate the sequential nature of individual schooling decisions and uncertainty about education costs and future earnings to help determine their importance. We report evidence on estimated option values from the recent empirical literature using rich panel data sources that enable analysts to answer questions that could not be answered with the cross section data available to Mincer in the 1960s." [Heckman, Lochner, and Todd (2006) p. 6 ]. However, these findings encourage a closer look at the impact of real option theory on human capital investment decision under uncertainty and extend the existing modeling to generate a more comprehensive theoretical framework. the impact of real option theory on

In line with Hogan and Walker (2007) we discuss how uncertain time processes (stochastic processes) determine the duration of schooling and - with the timing decision to leave school - the accumulation of human capital. As education is a continuous process, a year of schooling also means a year-long deferral of the entry into the labor market. The deferral includes an option to extend schooling for another year and to rise to a higher level of academic achievement. This option for further education is not only a chance to obtain a better expected income track, it also has an implicit value because the uncertainty of working life is postponed and the irreversible ${ }^{4}$ nature of leaving the school system

\footnotetext{
${ }^{2}$ Evidence (e.g. Katz, Autor, (1999)) shows that the functional form of the Mincer model no longer adequately describes labor earnings for U.S. workers. Further Heckman, Lochner, and Todd $(2003,2006)$ test and reject the assumptions required to use the Mincer model to estimate the internal rate of return. Heckman et al. (2008) emphasize that estimates should account for nonlinearities and non-separabilities in earnings functions, income taxes, and tuition.

${ }^{3}$ See e.g. Cunha, Heckman, and Navarro (2005), Carneiro, Hansen, and Heckman (2003), Belzil, Leonardi (2007a, b) or Hartog, Van Ophem, and Bajdechi, (2007).

${ }^{4}$ Practical reversability is also possible thanks to the inclusion of instruments such as exit
} 
is not realized. However, even if we are in some respects close to Hogan and Walker (2007), we depart from their analysis in various ways. 1) Hogan and Walker (2007) do not consider tuition costs or other human capital investment costs during education. In our approach schooling is linked to investment costs. Education implies the accumulation of an investment stream over time with additional years of schooling. 2) Costs may differ depending on the level of formal qualification. That is, we can distinguish between formal qualifications and the related costs. 3) In addition to a single Brownian motion we look at the complete earning profile consisting of the stochastic initial wage level when entering the labor market (entry-level wage), and the stochastic dynamics of income during working life. In this model both may be linked to educational attainment. 4) While Hogan and Walker discussed the threshold reaction for taxes and uncertainty, we explicitly determine the expected timing of market entry. Determining the first passage time allows us to include current market conditions like the current no-education wage (minimum wage) etc. in the discussion. Explicitly looking at the timing of market entry enables us to illustrate that the human capital decision is a sequential decision in time. Hence, the duration of schooling responds to all relevant economic variables and current stochastic market conditions. Looking at the first passage time as well as at the threshold reaction also shows that additional conditions are required to obtain a solution for the expected time of market entry. In other words, even if we can determine the threshold and the reaction of the threshold there is no guarantee this threshold will ever be reached in a more complex model (e.g. when including accumulative costs). 5) Comparative statics for all relevant variables are fully discussed analytically. No numerical discussion is needed. 6) As we are able to look at a sequence of education programs, each characterized by different earning profiles, sheepskin effects can be analyzed. 7) Entry into a higher education program often requires the successful prior completion of a lower qualification level. Hence the option value of an education is not only described by the earning profile of the education level in question, but also should include the option value of completing a higher qualification later on. This problem is discussed in the final section.

In order to discuss these problems we will proceed as follows. In section 2 we introduce the real option model to determine the expected time of leaving school for contiuous schooling. In section 3 we solve the model, and discuss comparative statics in section 4 . In section 5 we extend the model by introducing different levels of formal qualification and discuss the implications for the option values. In section 6 we conclude.

options in the model. However, as we would like to analyze a simple case we postpone this discussion to future research. 


\section{A model for time to leave school}

The education decision is an investment in human capital under uncertainty. Education is a choice of various time tracks of opportunities in an uncertain future. Investments in schooling and formal qualifications open up these various time tracks of opportunities and generate corresponding uncertain income streams. How many years should a person invest in schooling for a higher formal qualification? What is the expected duration of additional education and skills development outside of formal schooling programs? When is the best time to leave school and start working?

Modeling the timing the time of departure from the education system, we can describe the uncertain future development using various pattern of income streams depicted by different stochastic processes. As soon as working life starts, the individual will enter an uncertain labor market unaware of the income stream and the future success of their professional activity. However, they will have expectations about their income track that are linked to their formal academic qualification. The expected path of a college graduate will differ from that of someone with a high school diploma.

In this model towards a timing decision to leave school we suggest real option theory in terms of a dynamic programming model. The individual can defer their entry into the labor market and obtain more schooling. A student maximizes their present discounted value of lifetime earnings by deriving an optimal individual income threshold at which it is favorable to enter the labor market. Knowing that threshold, we can determine the expected duration of schooling and the corresponding level of formal academic qualification. This timing decision has two elements: 1) accumulated investment costs of schooling, 2) benefits of schooling with three components: a) schooling is a determinant of the level of the earnings path depicted by the entry-level wage when working life starts and b) schooling affects the dynamic development of the income stream and the resulting value of earnings during working life, and c) postponing working life through longer education, potentially achieving a better income track, or not yet being tied to a specific uncertain earnings stream has its own value, i.e. the option value of education. While a) and b) are the components of the expected earning profile, c) evaluates the advantage of remaining flexible.

At any point in time a student may decide to stay in school or to leave the education system and start working. Based on the expected net earning stream (including costs) and the option value of additional education, the student determines a threshold that triggers their decision to leave school and start working. That threshold is the entry-level wage a student needs to realize in order to have a positive evaluation of the complete education project. Hence they try to navigate their education process towards a situation where the realized entrylevel income matches the required income suggested by the threshold. At any moment the student compares these two values and decides whether it is beneficial to stay at school or start working and collect the expected income linked to their schooling investment. At any given moment the student reassesses their expected further education process. As the decision is repeated we observe a 
sequence of "stay-in-school decisions" that adds up to the entire duration of schooling and the eventual level of academic achievement. However, at any moment sudden (random) changes in conditions can also lead to an unexpected start of working life resulting in an unexpected lower level of education.

\subsection{Investment costs of schooling:}

If we define the time at which an individual decides about schooling as $t=$ 0 , total schooling costs for an individual student are the sum of the costs of each year until the end of their education. ${ }^{5}$ In this model $C$ is defined as the individual cost of a successfully completed year of schooling. Hence, a student with low capabilities would have to spend more to successfully complete a year of schooling. It can be assumed that these expenditures consist of tuition, extra private lessons, purchase of books, computers, materials and other related costs. Total investment expenditure for schooling $I(T)$ is dynamic and increases over time with each additional year of schooling. At time $T$, the end of the schooling phase, the current value of total schooling costs is

$$
I(T)=\int_{0}^{T} C e^{r(T-t)} d t+\bar{C},
$$

where $r$ is the risk-free interest rate and $\bar{C}$ are the given costs of successfully graduating, searching for an adequate job and realizing market entry. To focus on the major mechanics, taxes are not included in this simplest of models. However, this can easily be done by correcting the effective interest rate $r$, the costs of schooling ${ }^{6}$ and the income streams for taxes.

\subsection{Earnings profile}

Schooling not only generates costs. Schooling will also lead to a different earning profile. Schooling generates a) a differential in the entry-level wage when entering the labor market (move from A to B along the dotted line in figure 1), and b) schooling may lead to a change in the dynamic development and risk of the income stream during working life (dashed line in figure 1).

Entry-level wage: The entry-level wage, which is the wage when working life starts defines the initial level of the income path. Hence, the entry-level wage is the first of two elements of the earnings profile linked to educational achievement. With each additional (successful) year of schooling the entry-level wage increases, and hence the level of the earnings stream rises (see the dotted line in figure 1). ${ }^{7}$ However, even if another year of schooling can be expected

\footnotetext{
${ }^{5}$ Recent empirical studies suggest that education costs are an important ingredient of the education decision (see e.g. Heckman (2008)). By including the annual accumulative cost of schooling we depart from Hogan and Walker (2007), who do not consider education costs.

${ }^{6}$ If provided schooling costs are tax deductible.

${ }^{7}$ In figure 1 we consider the logarithm of income in order to draw income streams as linear curves.
} 


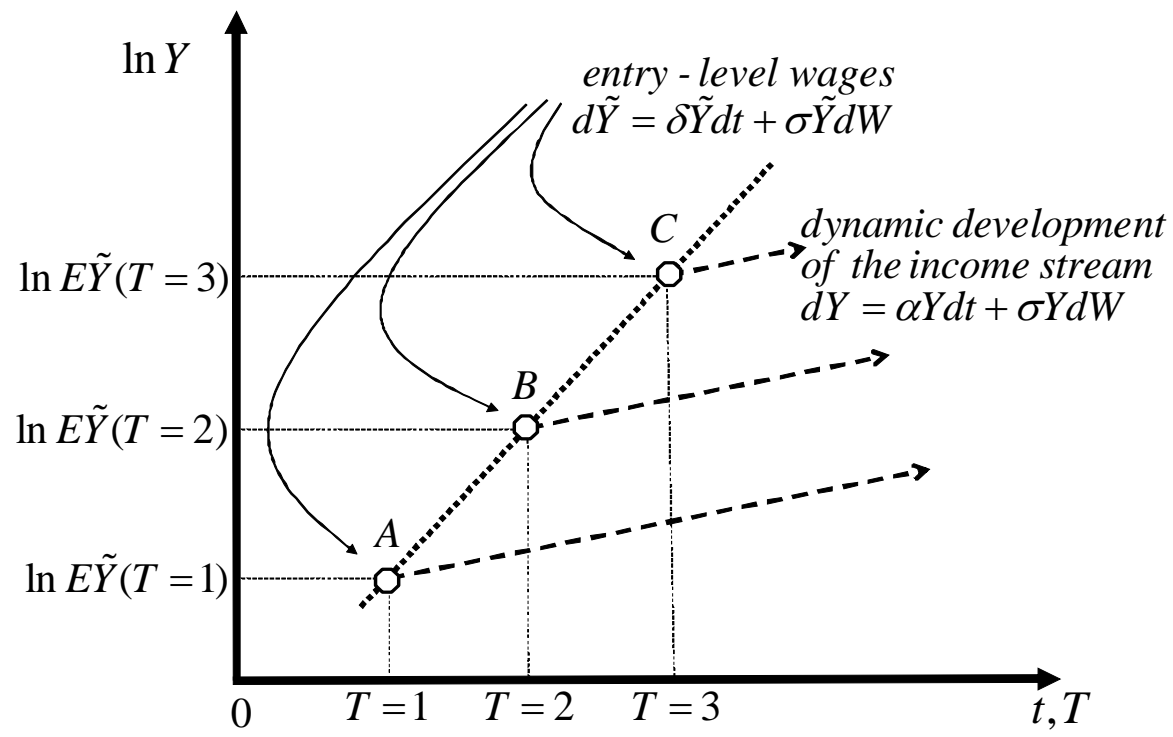

Figure 1: Earning profile: Entry-level wage and dynamics of income

to generate a marginal increase in entry-level wage by the rate $\delta$, many random elements determine the wage when entering the labor market. For the present simple case we describe the development of entry-level wages during schooling as a Brownian motion

$$
d \tilde{Y}=\delta \tilde{Y} d t+\sigma \tilde{Y} d W \quad \text { for } \quad 0<t<T
$$

where $\sigma$ denotes a constant volatility, $d W$ denotes the increments of a standard Wiener process, and $\delta>0$ is the expected marginal differential in income level with respect to marginal schooling time and educational improvement (expected rate of market reward). This change in the level of the income path is part of the total income reward generated by the schooling process. When a student plans their education at $t=0$ they expect from their market observation that one year of schooling will give them an entry-level wage of $E \tilde{Y}(T=1)$. For a market entry after two years of schooling they would expect an increase of the entry-level wage to the level $E \tilde{Y}(T=2)$. As we will later see for a given dynamic of the income stream, the expected marginal market reward $\delta$ and hence the differential in the level of the income path must be large ${ }^{8}$ enough to compensate sufficiently for the additional investment costs in human capital $C$.

\footnotetext{
${ }^{8}$ In this simplest of cases $\delta$ is fixed and the process is linear. However, a more realistic case would be $\delta(T)$ with a non-linear, maybe even s-shaped marginal reward of additional schooling. This would require the use of more general Ito processes to describe income development.
} 
Dynamics and value of the income stream: The second element of an individual earning profile is the dynamic development of the lifetime earnings stream. The dynamics of an individual income track are also connected to education. From the stylized facts we know that the dynamics of income during working life differ with respect to years of schooling and formal qualification levels. We assume that the lifetime earning path has systematic and random elements. Therefore, we model the lifetime earning path as a random process. Upon entry in the market $(t>T)$ the student faces a stochastic revenue stream which is characterized by an expected average growth rate $\alpha$ and elements of uncertainty depicted by a constant volatility $\sigma$. In general, individual income dynamics are driven by a stochastic earning process described by a geometric Brownian motion

$$
d Y=\alpha Y d t+\sigma Y d W \quad \text { for } \quad T<t,
$$

with $d W$ denoting the increments of a standard Wiener process. While in the real world an earnings profile would not be linear and decrease at the end of a working life or even become negative, we try to keep matters simple and assume $\alpha$ to be constant. For simplicity we also assume identical developments no matter how many years of schooling were completed. At this point neither do we distinguish between different years of schooling or achievement of formal educational levels such as primary, secondary or tertiary education. Hence in figure 1 earning tracks are characterized as parallel processes. In a more realistic setting we need to distinguish between different earning dynamics according to years of schooling or academic attainment. This will be examined later in this paper.

Once working life begins, the earning profile is fixed within the limits of the random process. Hence other opportunities are excluded and the economic value of the achieved education consists solely of its future income stream. For a risk neutral individual the gross value of human capital (education wealth) $V^{\text {gross }}$ is given by the expected present value of the wage-income earning stream $\{Y(t)\}$

$$
V^{\text {gross }}=E\left(\int_{T}^{\infty} Y e^{-r(t-T)} d t\right)=\frac{Y}{r-\alpha} ; \quad r>\alpha,
$$

with $r$ being the risk free interest rate. For simplicity the individual has an infinite lifespan.

\subsection{Option value of the waiting:}

Apart from affecting the earning profile, education time has a value of the option to defer market entry in order not to be tied to a lifetime earnings profile with the corresponding risk and irreversibility.

The option not to start working and not to irreversibly take the risk of embarking on a particular earning track has its own value - in correspondence to a 
firm's investment decision (Dixit (1989), and Dixit and Pindyck (1994)). Waiting may open up additional opportunities that could otherwise not have been foreseen and realized. Waiting also protects individuals from an "irreversible" departure from the education track. Once a student has left school they cannot return and are tied to the income and opportunity track they have chosen. In reality, this is surely not as strict as suggested by the expression "irreversible". 9 However, the end of schooling often also marks the end of a period of a personal life cycle characterized by a particular measure of independence and flexibility. The entry into working life marks the beginning of a new phase in life that is often connected to starting a family or acquiring responsibilities that go beyond the individual themselves. Returning to an education program is not impossible, but often has fairly high costs. Hence, leaving the system reflects the hope that one's present educational achievement will pay off sufficiently. If these expectations are not be fulfilled the student's investment costs become sunk costs. Therefore, waiting has a value because it offers the student flexibility. Further, once the student has decided to incur the sunk costs and enter the market, they could generally decide to exit if realized revenues are below expectation. In the current model, however, we assume that the student cannot exit the market voluntarily after entering - we thus preclude the exit option and leave it for a future extension to the present model. Accounting for the option value $F$ for the Brownian motion (2), the Hamilton-Jacobi-Bellman equation holds:

$$
r F d t=E(d F)
$$

This equation indicates that for a time interval dt, the total expected return on the investment opportunity is equal to the expected rate of capital appreciation.

\subsection{Decision problem}

For a student the education decision is a timing problem concerning whether to stay in school or enter the market. In order to clearly state the decision problem for this market entry we need to determine the net value of education $V$ (for any education achievement) and compare this value with the option value $F$.

To determine the expected net value of human capital the expected gross value (4) has to be adjusted for individual education costs $I(T)$ accumulated during the time of schooling (1). Hence, the net value of the earning stream of education investment is

$$
V=V^{\text {gross }}-I(T)
$$

In addition to the expected net value of human capital (net wealth of education) the third element of the decision problem, the option value of remaining in the education system, has to be considered. Further, as long as the student delays market entry they retain the option to enter the market without the risk of failure and embarking on the wrong earning stream.

\footnotetext{
${ }^{9}$ Exit options can be included.
} 
Given the expected net value of the earning stream (6) the option value $F$ of postponing market entry and obtaining a better qualification by adding another year of schooling can be determined by applying dynamic programming. ${ }^{10}$ Once the option value of waiting has been determined, the question of whether or not to wait for another period will be solved by the solution to:

$$
\max \{V(T), F(T)\}
$$

At any time during their education the student will compare the expected net value of human capital with the option value of remaining at school and not realizing an uncertain earning stream by starting work. As long as the option value of postponing the switch into working life and continuing one's education is higher than the value of realizing the uncertain income stream, the student will opt for another year of schooling. Solving this continuous decision problem determines the time of entry into the labor market and hence the expected duration of schooling including the decision about the level of formal qualification.

\section{Solving for the expected time to leave school}

Solving for the expected time of market entry as described above has two steps. First, for each duration of schooling we need to determine the income value $\left(Y^{*}(T)\right.$ threshold $)$ that would be needed to start working after a certain duration of schooling. This threshold is the required entry-level wage and hence the required level of the income path that would make one's education profitable. When the threshold is reached, the value of the earning stream becomes higher than the option value and hence market entry becomes more profitable than waiting and obtaining more education. Second, as the threshold would trigger the start of working life the student simultaneously observes the development of the relevant entry-level wage $\tilde{Y}(T)$. The student compares the threshold for their academic achievement with the corresponding current entry-level wage and verifies if the threshold has already been reached. Third, if they decide to stay at school they will predict the expected timing to leave school and hence the expected duration of schooling. We will model these aspects in the following section.

\subsection{Entry Threshold}

In order to determine the income value that triggers the switch we need to consider the standard conditions of a stochastic dynamic programming problem. In addition to the Hamilton-Jacobi-Bellman equation for the option value $F$ and applying Ito's lemma to $d F$ we have to use the well known boundary conditions,

\footnotetext{
${ }^{10}$ See the next section.
} 
namely (8), the value matching condition (9), and smooth pasting condition (10)

$$
\begin{aligned}
F_{\tau}(0) & =0 \\
F\left(Y^{*}\right) & =V^{\text {gross }}\left(Y^{*}\right)-I(T) \quad \text { value matching condition, } \\
\frac{d F\left(Y^{*}\right)}{d Y} & =\frac{d\left(V^{\text {gross }}\left(Y^{*}\right)-I(T)\right)}{d Y} \quad \text { smooth pasting condition. }
\end{aligned}
$$

to solve for the threshold income $Y^{*}$. The setting of the decision problem implies that the value of the uncertain earnings stream must be worth the switch from school to work. Hence, the wage level given by the Brownian motion must be high enough. Reaching this threshold triggers the change in strategy from more education towards entering the labor market. Therefore, determining this optimal threshold is the first part of a solution to the expected timing of market entry problem.

Proposition 1 For a constant accumulation of costs per year of successful schooling (1), a sequence of increasing earning levels through schooling described by (2), and an earning dynamics after market entry following (3) we can determine the threshold $Y^{*}(T)$ that would trigger the start of the earning/working process.

$$
\begin{aligned}
Y^{*}(T) & =\frac{\lambda}{\lambda-1}(r-\alpha)\left[\frac{C}{r}\left(e^{r T}-1\right)+\bar{C}\right]=\frac{\lambda}{\lambda-1}(r-\alpha) I(T), \\
\text { with } \lambda & =\frac{1}{2}-\frac{\delta}{\sigma^{2}}+\sqrt{\left(\frac{1}{2}-\frac{\delta}{\sigma^{2}}\right)^{2}+\frac{2 r}{\sigma^{2}}} \\
\text { and } r & >\delta
\end{aligned}
$$

Proof. For a proof see Appendix 1a).

Since each additional year of schooling adds to the total costs of education these costs are dynamic. The investment costs increase with years of schooling. Therefore, the threshold changes with the duration of schooling $T$, i.e. the threshold is a continuous function of $T$.

From the threshold function $Y^{*}(T)$ in Figure 2 we can see that an additional year of schooling drives up the threshold, that is, the student wants to be compensated for the additional year and costs by a higher entry-level income. In other words, the student would only complete an addtional year if they expect to be compensated by the market.

\subsection{Expected first-time realization of entry-level wages}

Once the student knows from the threshold at which entry-level wage they should start working, the question is when can they expect to obtain this income from the market for the first time.

As described above, the path of the entry-level wage is another random process. For a year of schooling and the investment costs $C$ the student may expect not only a different earnings dynamic during their working life (described 
by (3)). Income upon entry to the labor market is also expected to increase systematically by rate $\delta$ in (2) when time of schooling $T$ increases. As decribed in figure 1 both, the income dynamics and the entry-level wage define the complete earnings profile. That is, whenever a student considers their educational attainment they have to make a decision based on the time path of the entrylevel wage. As the initial income level is described by a random process and the threshold triggers market entry we are interested in the expected time when the threshold is reached for the first time referred to as the first passage time. As the threshold moves in a non linear way, it is hard to analytically determine the first passage time directly by the procedures suggested in Karatzas and Shreve (1991, p.196) or Karlin and Taylor (1975, p.363).

However, in order to analytically determine the first passage time in the next section we first suggest an instrument that allows for a non-linear development of the threshold and which leads to an easy graphic illustration. We call this instrument the Expected First Time Realization of entry-level wages. That is, for the random process $(\tilde{Y}$ see $(2))$ we derive the expected time of first realizing a certain entry-level wage $\tilde{Y}_{i}$ (given today's value $\tilde{Y}_{0}$ ). By using the Girsanov theorem we can derive the probability density function of $\tilde{T}_{i}{ }^{11}$ which is sometimes referred to as the Inverse Gaussian Distribution ${ }^{12}$.

Further, as we can determine the expected time of first realization of each value $\tilde{Y}_{i}>\tilde{Y}_{0}$ for the interval $\left.\left.\tilde{Y}_{i} \in\right] \tilde{Y}_{0}, \infty\right]$ we can write the expected first realization time as a function of $\tilde{Y}_{i} / \tilde{Y}_{0}$ :

Proposition 2 From the Brownian motion (2) we can derive the expected time of first realization $E \tilde{T}$ of each entry-level wage $\left.\left.\tilde{Y}>\tilde{Y}_{0}, \tilde{Y} \in\right] \tilde{Y}_{0}, \infty\right]$ as a function of $\tilde{Y} / \tilde{Y}_{0}$, and hence determine the expected time until any entry-level wage $\tilde{Y}$ is reached for the first time

$$
E \tilde{T}=\frac{1}{\delta-\frac{1}{2} \sigma^{2}} \ln \left(\frac{\tilde{Y}}{\tilde{Y}_{0}}\right) .
$$

Proof. For a proof see Appendix 2.

This expected time of first realization $E \tilde{T}$ for all values of entry-level wages can be drawn as the $E \tilde{T}$ curve in figure $2 \mathrm{a}$.

\subsection{Expected time to leave school}

Whenever a student plans their career they have to consider the time path of the entry-level wages and the threshold that will trigger market entry. We are interested in the expected time the threshold can be reached for the first time;

\footnotetext{
${ }^{11}$ An extensive discussion is offered by Karatzas and Shreve (1991, p.196) and Karlin and Taylor (1975, p.363).

12 The term "inverse Gaussian distribution" stems from the inverse relationship between the cumulant generating functions of these distributions and those of the Gaussian distributions. For a detailed discussion of the inverse Gaussian distribution see Johnson, Kotz, and Balakrishnan (1995) or Dixit (1993).
} 


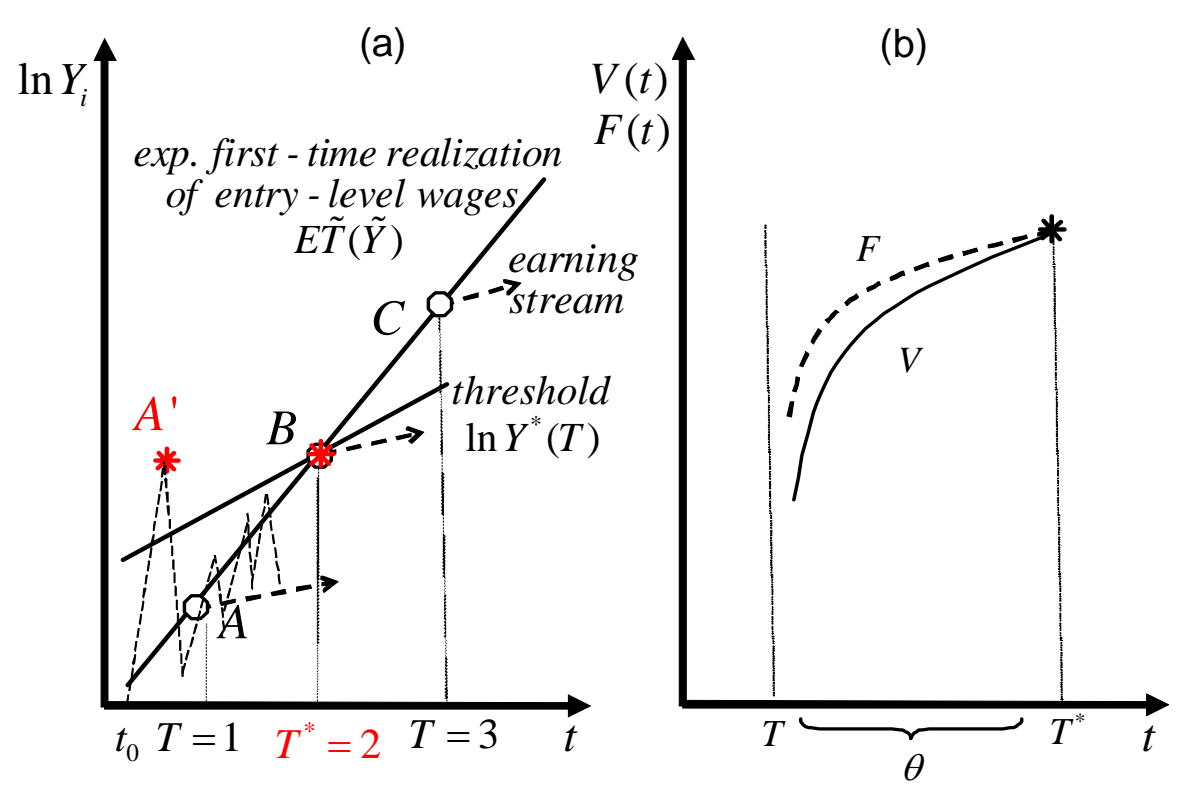

Figure 2: Threshold and income level

that is, we are interested in the so called first passage time (Karatzas and Shreve (1991, p.196), Karlin and Taylor (1975, p.363)). As decribed in figure 2a there are two types information available to determine the first passage time and hence the expected time of market entry. First, the student knows the threshold $Y^{*}(T)$ that triggers market entry for each duration of schooling $T$. Second, from the properties of the Brownian motion (2) the student knows the expected first-time realization of all inital income values, that is, the time when a certain entry-level wage $\tilde{Y}$ is expected to be reached for the first time $E \tilde{T}$.

Hence, if the entry-level wage $\tilde{Y}_{i}$ in question is expected to be reached for the first time at $E \tilde{T}_{i}$ and if $\tilde{Y}_{i}$ matches the value of $Y^{*}(T)$ at this particular time (for $T=E \tilde{T}_{i}$ ), we obtain the first passage time $T^{*}$. In other words, we obtain the expected time of market entry, which is when the entry-level wage can be expected to match the threshold for the first time (intersect of the expected first-time realization of inital income and the threshold in figure 2a). Correspondingly, as long as the first passage time has not been reached the option value $F$ is larger than the net value of current human capital (figure $2 \mathrm{~b})^{13}$.

Proposition 3 a) With the threshold $Y^{*}(T)$ (see (11)), the expected first-time

\footnotetext{
${ }^{13}$ As in Dixit and Pindyck ((1994), page 160) the curves F,V-I have an upward slope. However, under certain conditions they can also decrease because in this model costs are accumulated. For details see Appendix/Annotation 3.
} 
realization of inital income levels $E \tilde{T}$ (see (14)), and condition (16) and (17)14 there is an expected time to leave school and start working life $T^{*}=E(T)>$ 0 (first passage time) b) For each vector $\left(\alpha, r, \sigma, T^{*}, C, \tilde{Y}(0), \delta, \bar{C}\right)$ that fulfils a) there is a marginal environment, such that $T^{*}$ is an implicit function of $\alpha, \sigma, C, \tilde{Y}(0), \delta, \bar{C}$ and $r$.

$$
\begin{aligned}
T^{*}=T^{*}(\alpha, \sigma, C, \tilde{Y}(0), \delta r) \\
\frac{\lambda}{\lambda-1}(r-\alpha) \bar{C}>\tilde{Y}(0), \\
\bar{C} r>\bar{C}\left(\delta-\frac{1}{2} \sigma^{2}\right)>C .
\end{aligned}
$$

Proof. For a proof see Appendix 3.

In figure $2 \mathrm{a}$, a threshold that is higher than the expected entry-level wage reflects that learning costs during the education phase (before $T^{*}$ ) are not yet sufficiently compensated by the present entry-level wage. Hence the student will delay entering the market. In addition, condition (16) is important to understanding the logic of the decision problem. ${ }^{15}$ The decision in favor of any education level will only be positive if the minimum wage (no-education income $\tilde{Y}(0))$ is sufficiently small compared to education costs $(16) .{ }^{16}$

Further, as randomness is part of reality and random elements are modeled by a random process, the expected time of market entry $\left(T^{*}\right)$ is just an indicator of what may actually happen in future. As the future is partly random, an unexpected departure from education and subsequent market entry can easily happen at any time. In figure $2 \mathrm{a}$ we draw the time path of the expected first-time realization of entry-level wages for the present state of information at time $t_{0}$ by $E \tilde{T}$. A moment later, even if the individual expects to enter the market at $T^{*}$, a random occurrence in the labor market (e.g a business cycle boom) can push entry-level wages such that the threshold is reached and the student decides to start working immediately. In figure $2 \mathrm{a}$ this is displayed by the randomly upward shift of the realized market value at point $A^{\prime}$. The observed and hence realized market earnings exceed the threshold and hence education is terminated at $T=1$ and not - as expected before - at $T^{*}$. It is easy to find illustrative examples, such as the unexpected offer of an extraordinarily well-paid job. In

\footnotetext{
${ }^{14}$ Condition (17) seems restrictive. However, this sufficient condition reflects the simplifying assumption that schooling costs are constant for each year of schooling and the dynamics of the income process (3) do not change with more years of schooling. If income dynamics were positively related to the duration of schooling $\left(\alpha(T), \quad \alpha^{\prime}>0\right)$, this condition can be substituted by a more general simple condition. The explicit discussion of this condition and the implications is left for future research.

${ }^{15}$ Both conditions are required for the existence of a solution of the problem.

${ }^{16}$ This condition is needed for the threshold curve in figure 2 to start above the initial income level curve.
} 
this model the student will take this random opportunity at $T=1$ - no matter what they planned and expected before.

These simple examples also clearly illustrate that education decisions are timing decisions. Leaving education means taking the opportunity to realize the returns to education at the right time, even if the opportunity occurs accidentally.

\section{Determinants of the expected time to leave school}

In the previous chapter we determined the expected timing of learning and discussed the implications for academic attainment. In particular, we were able to show that the dynamic structure of the problem with special regard to risk and irreversibility is an important ingredient of the decision problem. In this section we examine the most important and most frequently discussed determinants of the expected duration of schooling. In particular, we look at the effects of risk, income dynamics, non-education wage levels, costs of schooling and the effect of changes in the marginal entry-level wage reward of schooling and interest rate changes.

Effect of income uncertainty $(\sigma)$ :

Proposition 4 With an increase in risk $\sigma$ the expected duration of schooling $T^{*}$ will increase:

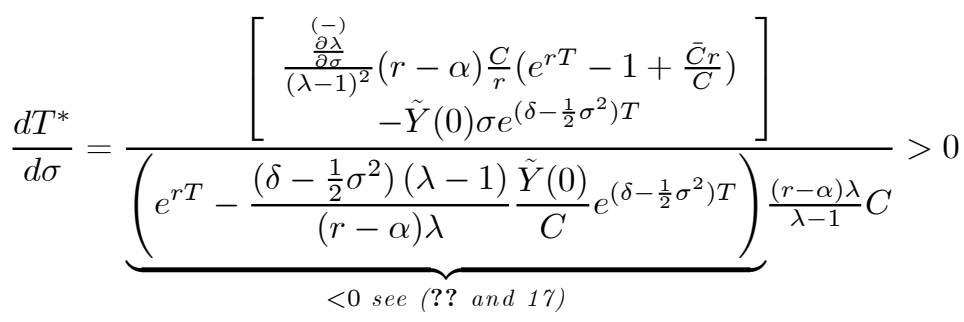

Proof. For a proof see Appendix 4.

The influence of rising risk - measured by the volatility of revenues - on the time of market entry can be expected and is consistent with Hogan and Walker (2007), but deviates from the results of Groot and Oosterbeek (1992) and Hanchane et al.(2006). An increasing income risk will devalue the earning stream and hence will require higher compensation reflected by an increased threshold. As long as the additional net rewards of longer education can compensate for the increase in the threshold, schooling will be continued. In figure $3 a$ the increasing risk will shift the threshold curve upwards and hence make a later market entry more attractive. Interestingly enough, this result is obtained even if we have no 
(a)

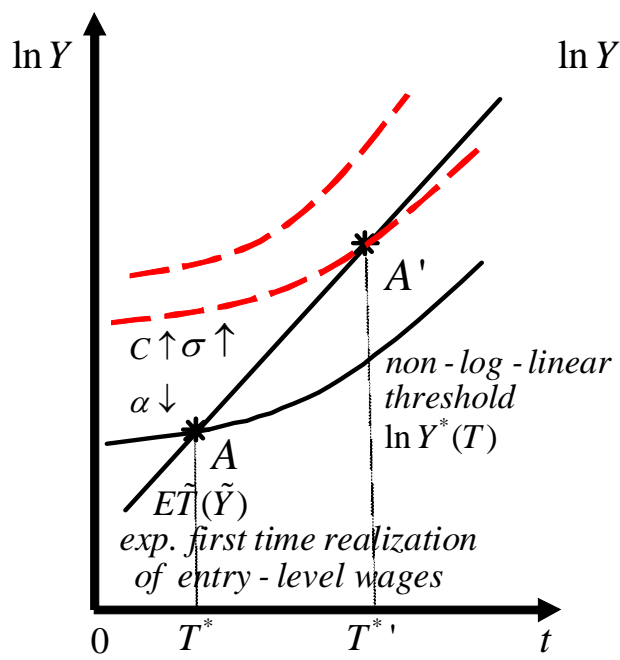

(b)

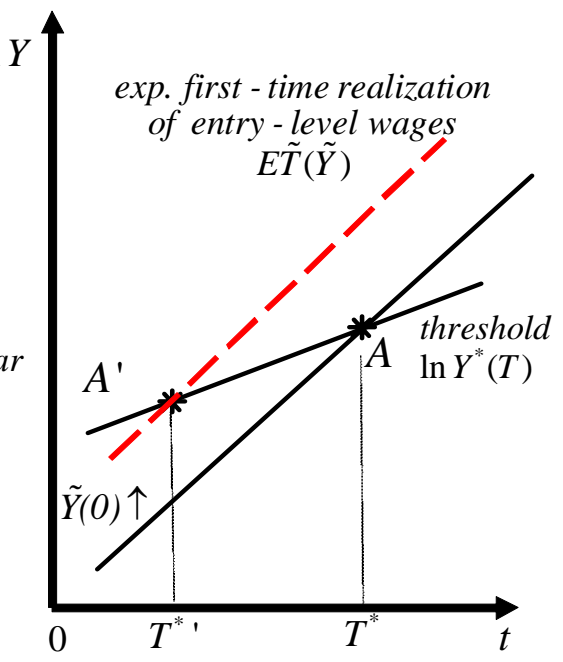

Figure 3: Earning profile: Entry-level wage and dynamics of income

explicit evaluation of risk by a utility function (and hence implicitly risk neutral agents). We do not need to make any assumption about the utility function and risk aversion. The pure option value and the irreversibility includes the effects of $\sigma_{i}$ in a different way.

\section{Effects of income growth $(\alpha)$}

Proposition 5 With an increase in the growth rate of future earnings, the expected duration of schooling $T^{*}$ will decrease:

$$
\frac{d T^{*}}{d \alpha}=\underbrace{\frac{\left[e^{r T}-1+\frac{\bar{C} r}{C}\right]}{\left(e^{r T}-\frac{\left(\delta-\frac{1}{2} \sigma^{2}\right)(\lambda-1)}{(r-\alpha) \lambda} \frac{\tilde{Y}(0)}{C} e^{\left(\delta-\frac{1}{2} \sigma^{2}\right) T}\right)}}_{<0} \frac{1}{(r-\alpha) r}<0
$$

Proof. For a proof see Appendix 5.

Declining general income growth affects the benefits of education. Lower earnings growth will decrease the expected present value of schooling. Lower growth and hence less attractive dynamics of the earning track will only pay off if entry-level wages increase. This shifts the threshold curve in figure $3 \mathrm{a}$ 
upwards. With a sufficient marginal reward $\delta$ the required threshold can still be reached after more years of schooling. This new earning profile, characterized by a higher entry-level wage to compensate for less rapid income growth, still justifies an even longer education.

Effects of an increasing $\alpha$ can also be described by another intuitively plausible story. If $\alpha$ increases, the expected net value of human capital would increase as well. As it is now easier to obtain the same value with lower investments, investments can be reduced.

Effects of the non-education (minimum) wage level $(\tilde{Y}(0))$

Proposition 6 A rising no-education (minimum) wage level $\tilde{Y}(0)$ will decrease the duration of education $T^{*}$ :

$$
\frac{d T^{*}}{d \tilde{Y}(0)}=\underbrace{\frac{1}{\lambda-1}(r-\alpha) C e^{\left(r-\delta+\frac{1}{2} \sigma^{2}\right) T}-\left(\delta-\frac{1}{2} \sigma^{2}\right) \tilde{Y}(0)}_{<0}<0
$$

Proof. For a proof see Appendix 6.

The minimum wage level $\tilde{Y}(0)$ represents the no education wage level when the schooling decision is made at $t=0$. If the agent did not obtain any schooling they could start working with this entry-level wage $\tilde{Y}(0)$ (figure $3 \mathrm{~b}$ ). In case of an increasing no education wage level educational attainment will decrease. This finding is intuitively expected. A rise in $\tilde{Y}(0)$ indicates (all else being equal) that no education achieves a higher level in income. The higher the no education wage path the less attractive a long education and the more attractive a quick market entry.

\section{Costs of schooling $(C)$}

Proposition 7 With increasing education costs the expected duration of schooling $T^{*}$ and hence academic achievement will rise:

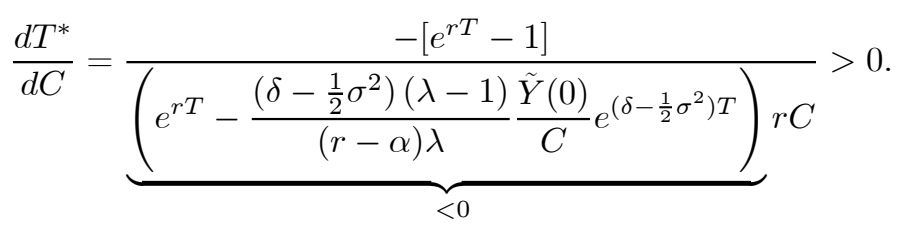

Proof. For a proof see Appendix 7.

As $C$ denotes the flow of investment costs for schooling, the reaction $\frac{d T^{*}}{d C}>0$ is not intuitively expected. In the standard approach higher investment expenditure would increase the opportunity costs of education and hence would make education less profitable. As a result educational attainment would be reduced. Therefore, this result can be regarded as a "tuition paradox". 
In this approach the decision problem is different. As the costs of schooling increase the student needs compensation from the market to stay in the system. Therefore, with increasing $C$, the required threshold shifts upwards in figure 3a. As long as the market rewards the outcome of additional schooling sufficiently ( $\delta$ is sufficiently high), both curves would still intersect at a later time. Even if the project becomes less profitable overall, the response to increasing costs will be to choose a higher income path (starting from a higher entry-level wage) generated by even more education. In other words, the new earning profile promises a sufficiently higher earnings path to compensate for the increase in costs and justify even more education. According to empirical results provided by Heckman et al. (2008) increasing costs could be partially compensated by higher investment in schooling and a corresponding rise in entry-level wage. Higher costs may lead to longer education as long as the rewards are sufficient.

However, this is the simplest case discussed in the proposition. The intuitively expected outcome of reducing education when costs increase can be also obtained as soon as the non-linear expansion of the threshold does not allow for an intersection. If a non-linear threshold is pushed upward as drawn by the dashed line in figure $3 \mathrm{a}$, increasing schooling costs cause the student to leave the education system. The shift in the threshold cannot be matched by a sufficient market reward and we find no intersect. For the individual conditions (costs etc.) of this student, there is no inner solution of the timing problem the student will leave school as soon as possible. This is the simplest solution to the "tuition paradox".

\section{Effects of marginal entry-level wage rewards of schooling $\delta$ :}

Proposition 8 An increase in the marginal entry-level wage reward for a year of schooling is generally ambiguous. However, an increase in $\delta$ will tend to postpone $T^{*}$. It encourages more education if $\frac{\tilde{Y}(0)}{C}$ becomes sufficiently large within the limits of conditions (16) and (25),

$$
\frac{d T^{*}}{d \delta}=\frac{\overbrace{\ln \left(\frac{\lambda-1}{\lambda} \frac{1}{r-\alpha} \frac{\tilde{Y}(0)}{\bar{C}}\right)}^{<0 \text { see }(16)}}{\left(\beta-\delta+\frac{1}{2} \sigma^{2}\right)^{2}}+\underbrace{\frac{1}{\beta-\delta+\frac{1}{2} \sigma^{2}}}_{(-)} \frac{\stackrel{(-)}{\partial \lambda}^{\frac{\partial \lambda}{\partial \delta}}}{(\lambda-1) \lambda}>0
$$

Proof. For a proof see Appendix 8.

Looking at condition (22) the sign of the reaction depends on the relative importance of the two terms, i.e., we can identify two different effects. On the one hand, as education generates an increasing market reward, the entry-level wage approaches the threshold more quickly [first term of (22)]. 
On the other hand, the threshold itself will be affected. Education time generates a higher reward and hence schooling duration becomes more valuable [second term of (22)]. Depending on these two relative effects we obtain a positive or negative total effect. In proposition (22) we suggest that costs are relatively high compared to the earning level $\tilde{Y}(0)$. Hence schooling will be extended. Further, as the threshold is - amongst other factors - determined by the evaluation of the education time, we can see how the real option approach affects the decision.

\section{Effects of the interest rate:}

Proposition 9 An increase in the interest rate is generally ambiguous. However, higher interest rates will reduce/increase education (decrease/increase $T^{*}$ ) if (26)/(27) holds

$$
\frac{d T^{*}}{d r}=\underbrace{\frac{1}{\beta-\delta+\frac{1}{2} \sigma^{2}}}_{(-)}[\underbrace{\frac{\stackrel{(+)}{\partial \lambda}^{\frac{\partial \lambda}{\partial r}}}{\lambda(\lambda-1)}-\frac{1}{(r-\alpha)}}_{=: X \gtreqless 0}] \gtreqless 0
$$

Proof. For proof see Appendix 9

As formally discussed in the appendix the reaction is generally ambiguous. However, we can determine conditions to obtain one or the other reaction.

\section{$5 \quad$ Formal qualifications and option values}

"For two reasons, the dynamic nature of schooling suggests that the returns to education may include an option value. First, the return to one year of school may include the potential for larger returns associated with higher levels of education when the returns to school are not constant across all schooling levels. For example, finishing high school provides access to college, and attending college is a necessary first step for obtaining a college degree. ... ." [Heckman, Lochner, and Todd (2006) p. 37]. ${ }^{17}$

\section{Earning profiles and formal qualification levels}

The purpose of this section is to account for discontinuities and non-linearities in the decision problem. After the general discussion of a timing decision to leave

\footnotetext{
${ }^{17}$ The second reason to implment option theory in the human capital decision is already discussed in the above model: "... Second, when there is uncertainty about college costs or future earnings and when each additional year of schooling reveals new information about those costs or earnings, the full returns to schooling will include the expected value of newly revealed information that can be acted on." [Heckman, Lochner, and Todd (2006) p. 37].
} 
school we now extend the model to include different levels of formal qualification. Wages and costs of schooling may not only increase with years of schooling but also may jump, after attaining a certain education level, to a higher income stream. The so-called "sheepskin effect" seems of increasing importance in the recent empirical discussion. Although one branch of research argues that there is a linear relationship between wages and years of schooling, recent findings support the hypothesis of non-linearities in incomes, which occur especially with high school and college completion. ${ }^{18}$ Further, it seems that both the years of schooling and the achieved level of formal qualification determine the two elements of the earnings profile, namely the entry-level wage when entering the labor market and the earnings dynamics during working life. Therefore, the simultaneous consideration of years of schooling and completion of different levels of formal qualification is the natural next step in extending the model.

In this extension timing is an optimal choice of a sequence of investments with varying earning profiles connected with the completion of different levels of formal qualification. In general the above model can be regarded as a model for only one level of formal qualification. In order to consider more levels we simply symmetrically add other earning profiles to decide on the full set of opportunities. Specifically, for each level of formal qualification $i$ (e.g. secondary education) we assume specific costs $C_{i}$ for a successful year of schooling expecting that a specific earning profile is connected to this formal qualification level. Again, a student observes that for each formal qualification level $i$ a year of additional schooling will increase their entry-level wage $\tilde{Y}_{i}$ according to the Brownian motion ${ }^{19}$

$$
d \tilde{Y}_{i}=\delta_{i} \tilde{Y}_{i}+\sigma_{i} \tilde{Y}_{i} d W \text { for } t<T_{i}
$$

where $T_{i}$ denotes the years of schooling required to attain the formal qualification level $i$ (e.g in many secondary education programs students have to study four years, hence $\left.T_{i}=4\right)$. Further, the dynamic development of income $Y_{i}$ during working life for each level of formal qualification $i$ is once again described by $^{20}$

$$
d Y_{i}=\alpha_{i} Y_{i} d t+\sigma_{i} Y_{i} d W \quad \text { for } \quad T_{i}<t .
$$

It now becomes apparent that the individual earning profiles associated with different levels of formal qualification may be characterized by different marginal rewards in entry-level wages $\left(\delta_{i}\right)$, different growth patterns $\left(\alpha_{i}\right)$ and different risks $\left(\sigma_{i}\right)$.

In figure 4 we describe an example of three levels of formal qualification (primary, secondary and tertiary education, $i=1,2,3)$ to illustrate the additional

\footnotetext{
${ }^{18}$ See e.g. Heckman (1995); Heckman, Lochner, and Todd (2006, 2008); Denny, Harmon (2001); Skalli (2007); Ferrer, Riddell (2008); Silles (2008).

${ }^{19}$ Each level of formal qualification is modeled symmetrically to the reference model above. Therefore see also (2) for only one level of formal qualification.

${ }^{20}$ See again $(3)$.
} 


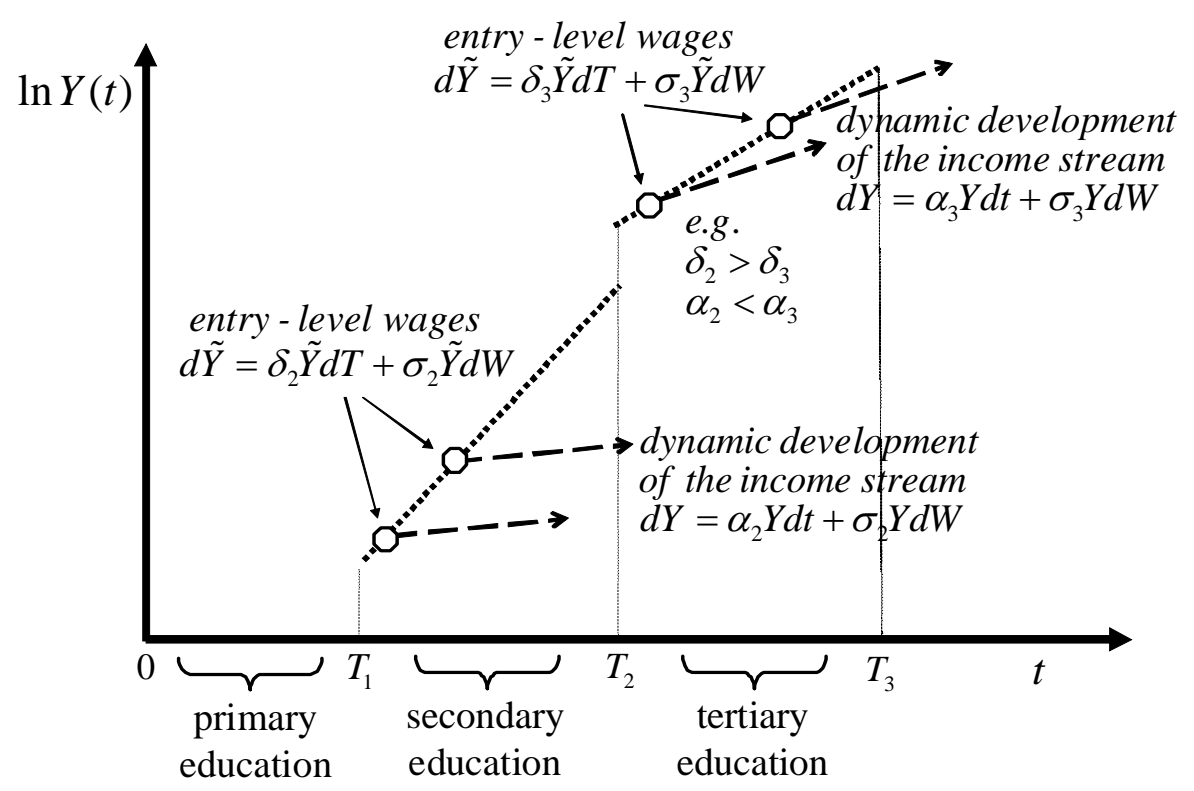

Figure 4: Earning profiles for various levels of formal qualification

effects of completing of various qualification levels. Figure 4 describes various profiles for various years of schooling and levels of formal qualification. When a specific number of years $T_{i}$ is reached the student attains a formal qualification $i$ (e.g. secondary education). In this diagram for a higher level of formal qualification we assume a smaller $\delta_{i}$ and an larger $\alpha_{i}$. As a result, students studying at e.g. secondary level are rewarded for additional schooling with a relatively strong boost in entry-level wages, but will also expect relatively low income dynamics. However, other patterns are possible.

As in the previous chapter we can now take the entry-level wage curve $\tilde{Y}_{i}(T)$, determine the threshold curve $Y_{i}^{*}(T)^{21}$ and derive the expected time of schooling for each level of qualification $T_{i}^{*}$. For our example involving three levels of formal qualification figure 5 a gives the results in the $V, F-T$ plane. When education starts, a student will make a decision concerning the anticipated duration of schooling and the corresponding formal academic qualification. Their plan uses available information and takes into account potential irreversibility.

Figure 5a exhibits three profiles of net value of human capital (net wealth of education) $V_{i}(i=1,2,3$ see $(6))$ and the corresponding option value, one

\footnotetext{
${ }^{21}$ To keep the discussion simple at this point, we do not explicitly consider the option value of a total sequence, such that the completion of one level of formal qualification is required to start the next. This extension would increase the option value. For the discussion of the additional option value of completing a formal qualification see the discussion at the end of this section.
} 
for each level of formal qualification. At each moment a student will compare the net value of human capital when starting work straight away $V_{i}(T)$, with the value of the option of staying in school and obtaining more education $F_{i}(T)$ (see $(7)$ ). As long as the option value is higher than the net value of human capital the student will defer their decision to enter the labor market. Waiting and completing more years of schooling is the dominant strategy. In figure 5a we can follow this consideration from the start. If $V_{1}<F_{1}$ the student will defer entering the labor market. They will do so until point $A$ is reached. At point $A$ the value matching condition (9) and smooth pasting condition (10) simultaneously hold and an optimum is reached. If there are no other alternatives, $A$ would be the expected duration of schooling at primary level. However, there are alternatives. The student could finish primary education and then opt for additional schooling at secondary level. As the value of a completed primary education and some secondary-level schooling $\left(F_{2}\right)$ is higher than $V_{1}$ at point $A$ the student will complete primary education and enter secondary education. For this higher, secondary education level they go through the same considerations as before. Comparing the value of entering the labor market with the option values of additional education and the attendant opportunities, they will opt for additional years of schooling in the example of figure 5a. The expected time of schooling $T^{*}$ is reached once they have gained a formal tertiary qualification plus some additional schooling time. Since for each formal qualification the timing of leaving school and entering the labor market can be determined, it is easy to pick the optimal point according to the decision rule. $G$ is the stable optimal solution to this dynamic decision problem, which includes irreversibility and uncertainties.

Moreover, as the formal qualification $i=3$ (tertiary education) is reached at $T=T_{i=3}$ and $T^{*}>T_{i=3}$ the student decides to have more than the minimum years of schooling required to complete tertiary education. If $\theta=T^{*}-T_{i}>0$ are the additional years of schooling beyond the formal minimum requirement, why these extra years of education? In real life we find many education activities that are not directly connected to a formal qualification. Internships, a language course abroad, time spent on searching for a job and collecting information and even time spent on developing one's personal profile can extend a students's duration of education beyond the minimum required for a given formal qualification. Therefore, these additional years are part of the value of the waiting option after formal education has been obtained. The additional years $\theta$ do not necessarily take place after a formal education has ended; they can, and in fact normally do, take place at any time during the formal education program.

We can also think of other examples especially at tertiary level when an extra year may be completed during the official term of study. At universities many students take a sabbatical from their home program. In this case the extra year is taken before formal graduation. The extra year will extend the time until the formal qualification is completed. In this case working life still starts straight after graduation, which seems to be the normal pattern. Therefore, equation (15) is the number of school years including those elements that are not formally 

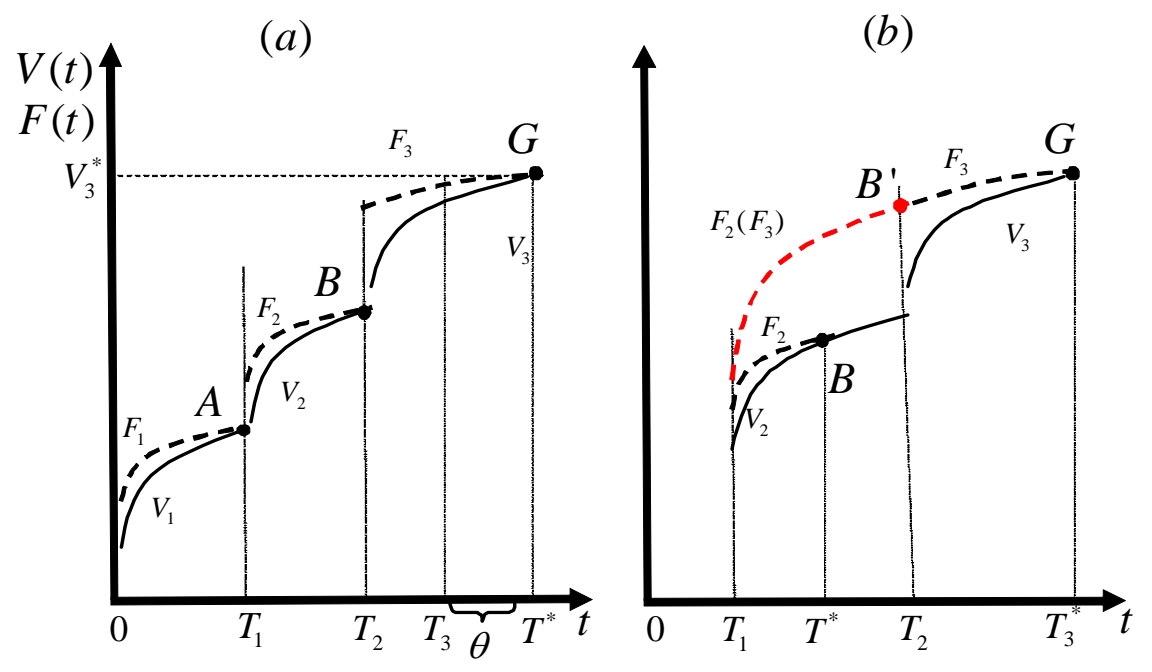

Figure 5: Sequence of formal qualification levels

required for formal qualification at secondary level.

Option value of completing a formal qualification Regarding a sequence of formal qualification levels another important phenomenon can be integrated into this approach concerning schooling decision under uncertainty. Often the entry into a higher education program requires the prior successful completion of a lower qualification level. E.g. if a student wants to start a college degree, they need to graduate from high school beforehand. From the perspective of a sequential decision the option value of an education is not only described by the earning profile of the education level in question, but also includes the option value of completing a higher qualification later on. In other words, when the student considers the option value of completing of secondary education $F_{2}$, and completing secondary education is a prerequisite for tertiary education, they consider the potential income stream for this qualification as well as for the option of this qualification but also for the option of tertiary education $F_{3}$. "Our findings suggest that part of the economic return to finishing high school or attending college includes the potential for completing college and securing the high rewards associated with a college degree. Both sequential resolution of uncertainty and non-linearity in returns to schooling can contribute to sizeable option values." [Heckman, Lochner, and Todd, (2006) p. 7].

Hence the option value of secondary education includes an income component connected to secondary education, and the option value of starting tertiary 
education, $F_{2}=F_{2}\left(F_{3}, V_{2}\right)$. While the option value of tertiary education can be determined from the earning profile and the expected duration of tertiary education $^{22}$,

$$
F_{3}=\frac{1}{\left(r-\alpha_{3}\right)^{\lambda_{3}}}\left(\frac{\left(\lambda_{3}-1\right)}{\lambda_{3}}\right)^{\lambda_{3}} I_{3}(T)^{\left(1-\lambda_{3}\right)}\left[\frac{\lambda_{3}}{\left(\lambda_{3}-1\right)}-1\right]\left(\tilde{Y}_{3}\right)^{\lambda_{3}}
$$

the decision on the duration of secondary education will include this option value in the boundary conditions:

$$
\begin{aligned}
F_{2}(0) & =0 \\
F_{2}\left(Y_{2}^{*}\right) & =F_{3}\left(Y_{2}^{*}\right)-I_{2} \\
F_{2}^{\prime}\left(Y_{2}^{*}\right) & =F_{3}^{\prime}\left(Y_{2}^{*}\right)
\end{aligned}
$$

As can be derived from these conditions, this additional option value will push up the threshold and increase the expected duration of schooling at secondary level.

However, as mentioned before (figure 2) this menu of choices reflects long term expectations regarding years of schooling and completing formal education, yet the future is uncertain. Therefore, this plan is valid only under the present conditions of period $t=0$. It is a preliminary plan which needs to be revised permanently. One period later the optimal plan and the marginal decision to wait or start working is adjusted to account for new information and conditions. The sequence of marginal decisions terminates when the decision to switch is made. Then the earnings track has been chosen irreversibly. In other words, even if the plan suggests that schooling should be expected to be terminated after three years (e.g. after tertiary education is completed), a sudden change in conditions can terminate schooling overnight, leading to an unexpected entry into working life.

\section{Summary}

The major purpose of this paper is to derive a timing rule for leaving school and entering the labor market. Thus, we answer the question: How long should one go to school? Considering uncertainty of future developments we use real option theory in terms of a dynamic programming model. Schooling expenditure, earning streams and the option values of remaining in education determine the expected time to leave school and one's academic achievement. In addition to the recent literature our approach includes continuous schooling costs that depend on individual abilities and qualification programs. Education attainment generates differing ex ante income profiles each consisting of a) an uncertain

\footnotetext{
${ }^{22}$ For further information see Appendix 1b).
} 
movement of entry-level wages during one's education time, and b) the uncertain dynamics of the earning profile once working life has started. Both components can reflect rewards for education and can both be described by a specific Brownian motion. At all times an individual can decide sequentially to remain in school or leave the education system and start working. However, once the decision to leave the education system is made, the decision is irreversible. As the individual has expectations regarding the first-time realization of stochastically moving entry-level wages and can determine the optimal threshold, the expected duration of schooling can be identified. While the existing literature discusses pure threshold reactions for e.g. taxes and uncertainty, we explicitly determine the expected timing of market entry (first passage time). This allows an analysis of the effects of current market conditons and illustrates that the human capital decision is a sequential decision in time. Comparative statics for all relevant variables are discussed fully analytically. No numerical discussion is needed. E.g. increasing education costs (or increasing risk) may increase human capital investments as long as the marginal reward for another year of schooling is sufficiently high and hence additional costs (or risk) are sufficiently compensated by income. However, if costs become too high there is no inner solution and the education process terminates. Further, as we are able to look at a sequence of education programs, each characterized by various cost and income profiles of formal qualification levels, discontinuities and sheepskin effects can be analyzed. As entry into a higher education program often requires the prior successful completion of a lower qualification level, the option value of an education is not only described by the earning profile of the education level in question, but also should include the option value of completing a higher qualification later on. This problem is discussed in the final section.

\section{References}

[1] Becker, G., (1975), Human Capital: a Theoretical and Empirical Analysis, with special Reference to Education, New York: National Bureau of Economic Research.

[2] Belzil, C., Leonardi, M., (2007a), Can Risk Aversion Explain Schooling Attainments? Evidence from Italy, Labour Economics, 14 (6), 957-70

[3] Belzil, C., Leonardi, M., (2007b), Risk Aversion and Schooling Decisions, IZA Discussion Paper No. 2994, 2007.

[4] Card, D., (2001) Estimating the Return to Schooling Progress on some Persistent Econometric Problems, Econometrica, 69 (5), 1127-1160.

[5] Carneiro, P., Hansen, K., Heckman, J.J. (2003). "Estimating distributions of treatment effects with an application to the returns to schooling and measurement of the effects of uncertainty on college choice". International Economic Review 44 (2), 361-422. 
[6] Comay, Y., A. Melnik, M. A. Pollatschek (1973), "The Option Value of Education and the Optimal Path for Investment in Human Capital", International Economic Review, 14, (2), 421-435.

[7] Cunha, F., J. J. Heckman, S. Navarro (2005). Separating uncertainty from heterogeneity in life cycle earnings, The 2004 Hicks Lecture. Oxford Economic Papers 57 (2), 191-261.

[8] Denny, K., Harmon,C., (2001), Testing for Sheepskin Effects in Earnings Equations: Evidence for Five Countries, Applied Economic Letters 8, 635637.

[9] Dixit, A. K., (1993) The art of smooth pasting, Chur, Switzerland: Harwood academic publishers.

[10] Dixit, A. K.; Pindyck R. S., (1994), Investment under uncertainty, Princeton Press.

[11] Eaton, J., Rosen, H., (1980), Taxation, Human Capital and Uncertainty, The American Economic Review 70, no. 4.

[12] Ferrer, A., Riddell, W. C., (2008), Education, Credentials, and Immigrant Earnings, Canadian Journal of Economics 41, iss. 1, 186-216.

[13] Groot, W., Oosterbreek, H., (1992), Optimal Investment in Human Capital Under Uncertainty, Economics of Education Review 11(1), 41-49.

[14] Hanchane, S.; Lioui, A.; Touahri, D. (2006), Human Capital as a Risky Asset and the Effect of Uncertainty on the Decision to Invest, LEST Working Paper.

[15] Hartog, J.; Van Ophem, H.; Bajdechi, S. M., (2007), Simulating the Risk of Investment in Human Capital, Education Economics, 15 (3) , 259-275.

[16] Heckman, J. J., Lochner, L. J., Todd, P. E. (2003), Fifty years of Mincer earnings regressions. Technical Report 9732, National Bureau of Economic Research.

[17] Heckman, J. J., Lochner, L. J., Todd, P. E. (2006), Earnings equations and rates of return: The Mincer equation and beyond. In: E. A. Hanushek and F. Welch (Eds.), Handbook of the Economics of Education, Chapter 7, pp. $307-458$.

[18] Heckman, J, Lochner, L., Todd, P., (2008), Earning Functions and Rates of Return, Journal of Human Capital 2(1), 1-128.

[19] Hogan, V., Walker, I., (2007), Education Choice under Uncertainty: Implications for Public Policy, Labour Economics 14, 894-912.

[20] Jacobs, B., (2007), Real Options and Human Capital Investment, Labour Economics 14, 913-925. 
[21] Johnson, T., (1970), Returns from Investment in Human Capital, American Economic Review, 60(4), 546-560.

[22] Karatzas and Shreve (1996), Brownian Motion and Stochastic Calculus, Springer.

[23] Johnson, N. L., Kotz, S., Balakrishnan, N., (1995), Continuous Univariate Distributions, 2nd edition, New York: John Wiley \& Sons, Inc.

[24] Karlin, S., Taylor, H.M., (1975), A First Course in Stochastic Processes, Academic Press.

[25] Kodde, D.A., (1985), Microeconomics Analysis of Demand for Education, Ph.D. thesis, Erasmus University Rotterdam.

[26] Levhari, D., Weiss, Y., (1974), The Effect of Risk on the Investment in Human Capital, The American Economic Review 64(6), 950-963.

[27] Mincer, J., (1974), Schooling, Experience and Earnings, New York: National Bureau of Economic Research.

[28] Silles, Mary (2008), Sheepskin Effects in the Returns to Education, Applied Economics Letters 15, iss. 1-3, 217-219.

[29] Skalli, A., (2007), Are Successive Investments in Education Equally Worthwhile? Endogenous Schooling Decisions and Non-Linearities in the Earnings-Schooling Relationship, Economics of Education Review 26 215231 .

[30] Weisbrod, B.A. (1962). "Education and investment in human capital". Journal of Political Economy 70 (5),

[31] 106-123.

[32] Williams, J.T., (1979), Uncertainty and the Accumulation of Human Capital over the Life Cycle. 


\section{Appendix}

\subsection{Appendix 1: Net present and option value}

\subsection{1 a) Proof of Proposition 1 and Derivatives of $\lambda$}

The value of the earnings stream is determined by

$$
\begin{aligned}
V^{\text {gross }} & =E \int_{T}^{\infty} e^{-r(t-T)} Y d t \\
& =\frac{Y}{r-\alpha}
\end{aligned}
$$

For the option values $F$ the Hamilton-Jacobi-Bellman equation for the Brownian motion of 2 holds:

$$
r F=\frac{1}{d t} E(d F)
$$

From Ito's Lemma and because of $E(d W)=0$ we obtain the following differential equation:

$$
\begin{aligned}
\underbrace{\frac{\partial F}{\partial t}}_{=0}+\delta \tilde{Y} \frac{\partial F}{\partial \tilde{Y}}+\frac{1}{2} \sigma^{2} \tilde{Y}^{2} \frac{\partial F}{\partial \tilde{Y}^{2}}-r F & =0 \\
\delta \tilde{Y} \frac{\partial F}{\partial \tilde{Y}}+\frac{1}{2} \sigma^{2} \tilde{Y}^{2} \frac{\partial F}{\partial \tilde{Y}^{2}}-r F & =0
\end{aligned}
$$

This is a second-order homogenous ordinary differential equation with a free boundary.

A general solution to this differential equation is

$$
F=\tilde{\sim}^{\lambda}
$$

$\sim \lambda$

$B Y$ solves the homogenous differential equation.

$$
\begin{aligned}
\delta \tilde{Y} B \lambda \tilde{Y}^{\lambda-1}+\frac{1}{2} \sigma^{2} B \tilde{Y}^{2} \lambda(\lambda-1) \tilde{Y}^{\lambda-2}-r B \tilde{Y}^{\lambda} & =0 \\
\delta \lambda+\frac{1}{2} \sigma^{2} \lambda(\lambda-1)-r & =0
\end{aligned}
$$

$$
\Leftrightarrow \quad \lambda=\frac{1}{2}-\frac{\delta}{\sigma^{2}}+\sqrt{\left(\frac{1}{2}-\frac{\delta}{\sigma^{2}}\right)^{2}+\frac{2 r}{\sigma^{2}}}>1 \quad \text { see }(12)
$$

with $\delta<r \quad$ see $(13)$ 
As $\tilde{Y}$ goes to zero, $F$ tends to 0 . This implies that the negative root of the characteristic polynomial should have no influence on $F$ as $\tilde{Y}$ tends to zero.

Besides $\lambda>1 \Leftrightarrow r>\delta$ :

$$
\begin{aligned}
\frac{1}{2}-\frac{\delta}{\sigma^{2}}+\sqrt{\left(\frac{1}{2}-\frac{\delta}{\sigma^{2}}\right)^{2}+\frac{2 r}{\sigma^{2}}} & >1 \\
\sqrt{\left(\frac{1}{2}-\frac{\delta}{\sigma^{2}}\right)^{2}+\frac{2 r}{\sigma^{2}}} & >\frac{1}{2}+\frac{\delta}{\sigma^{2}} \\
r & >\delta
\end{aligned}
$$

For the derivatives of $\lambda$ we obtain:

$$
\begin{gathered}
\frac{d \lambda}{d \delta}=-\frac{\left[\left(\frac{1}{2}-\frac{\delta}{\sigma^{2}}\right)^{2}+\frac{2 r}{\sigma^{2}}\right]^{-\frac{1}{2}}}{\sigma^{2}} \lambda<0 \\
\frac{d \lambda}{d r}=\left[\left(\frac{1}{2}-\frac{\delta}{\sigma^{2}}\right)^{2}+\frac{2 r}{\sigma^{2}}\right]^{-\frac{1}{2}} \frac{1}{\sigma^{2}}>0 \\
\frac{d \lambda}{d \sigma}=\frac{2 \delta\left[\left(\frac{1}{2}-\frac{\delta}{\sigma^{2}}\right)^{2}+\frac{2 r}{\sigma^{2}}\right]^{-\frac{1}{2}}}{\sigma^{3}}\left[\left[\left(\frac{1}{2}-\frac{\delta}{\sigma^{2}}\right)^{2}+\frac{2 r}{\sigma^{2}}\right]^{\frac{1}{2}}+\frac{1}{2}-\frac{\delta}{\sigma^{2}}-\frac{r}{\delta}\right]<0
\end{gathered}
$$

At the investment trigger point $Y^{*}$ the value of the option must equal the net value obtained by exercising it (value of the active project minus sunk cost of the investment). Hence the following must hold:

$$
\begin{aligned}
F\left(Y^{*}\right) & =V^{\text {gross }}\left(Y^{*}\right)-I(T) . \\
& =\frac{Y^{*}}{r-\alpha}-\frac{C}{r}\left(e^{r T}-1\right)-\bar{C} \\
B\left(Y^{*}\right)^{\lambda} & =\frac{Y^{*}}{r-\alpha}-\frac{C}{r}\left(e^{r T}-1\right)-\bar{C}
\end{aligned}
$$

Besides for $I(T)>0$ we have to assume that $\bar{C}>\frac{C}{r}$.

The smooth-pasting condition requires that the two value functions meet tangentially:

$$
\begin{aligned}
\left(F\left(Y^{*}\right)\right)^{\prime} & =\left(V^{\text {gross }}\left(Y^{*}\right)\right)^{\prime} \\
& \Leftrightarrow B \lambda\left(Y^{*}\right)^{\lambda-1}=\frac{1}{r-\alpha}
\end{aligned}
$$

This implies

$$
B\left(Y^{*}\right)^{\lambda}=\frac{Y^{*}}{(r-\alpha) \lambda}
$$


Now we compute the threshold $Y^{*}$ :

$$
\begin{aligned}
\frac{Y^{*}}{r-\alpha}-\frac{C}{r}\left(e^{r T}-1\right)-\bar{C} & =\frac{Y^{*}}{(r-\alpha) \lambda} \\
Y^{*}(T) & =\frac{\lambda}{\lambda-1}(r-\alpha)\left[\frac{C}{r}\left(e^{r T}-1\right)+\bar{C}\right]=\frac{\lambda}{\lambda-1}(r-\alpha) I(T)
\end{aligned}
$$

with $\ln I(T)$ being convex and hence $\ln Y^{*}(T)$ being a convex function in $T$ :

$$
\begin{aligned}
& \frac{\partial \ln I}{\partial T}=\frac{C e^{r T}}{\frac{C}{r}\left(e^{r T}-1\right)+\bar{C}}>0 \\
& \frac{\partial^{2} \ln I}{\partial T^{2}}=\frac{\operatorname{Cre}^{r T}\left(\frac{C}{r}\left(e^{r T}-1\right)+\bar{C}\right)-C^{2} e^{2 r T}}{\left(\frac{C}{r}\left(e^{r T}-1\right)+\bar{C}\right)^{2}} \\
& =\frac{C e^{r T}(r \bar{C}-C)}{\left(\frac{C}{r}\left(e^{r T}-1\right)+\bar{C}\right)^{2}}>0 \text { (convex) as we assume (17) } \\
& \lim _{T \rightarrow \infty} \frac{\partial \ln I}{\partial T}=\lim _{T \rightarrow \infty} \frac{C e^{r T}}{\frac{C}{r}\left(e^{r T}-1\right)+\bar{C}}=\lim _{T \rightarrow \infty} \frac{r e^{r T}}{\left[e^{r T}-1+\frac{r \bar{C}}{C}\right]} \\
& =\lim _{T \rightarrow \infty} \frac{r e^{r T}}{\left[1+\frac{-1+\frac{r \bar{C}}{C}}{e^{r T}}\right] e^{r T}}=r
\end{aligned}
$$

\subsection{2 b) Option value for different income levels}

According to Dixit, Pindyck (1994, ch. 10) investment decisions can be made sequentially, for example for three different levels of income.

We compute the option value $F_{3}$ corresponding to the entry-level wage path $\tilde{Y}_{3}$. From the value matching condition we obtain

$$
\begin{aligned}
B_{3}\left(Y^{*}\right)^{\lambda} & =V^{\text {gross }}\left(Y^{*}\right)-I_{3}(T) \\
& \Leftrightarrow \quad B_{3}=\frac{V^{\text {gross }}\left(Y^{*}\right)}{\left(Y^{*}\right)^{\lambda_{3}}}-\frac{I_{3}(T)}{\left(Y^{*}\right)^{\lambda_{3}}} .
\end{aligned}
$$

Now we can plug in the derived investment threshold $Y^{*}(T)$ :

$$
\begin{aligned}
B_{3}= & \frac{\left(\frac{\lambda_{3}}{\lambda_{3} \lambda-1}\left(r-\alpha_{3}\right) I_{3}(T)\right)^{1-\lambda_{3}}}{r-\alpha_{3}}-\frac{I_{3}(T)}{\left(\frac{\lambda_{3}}{\lambda_{3}-1}\left(r-\alpha_{3}\right) I_{3}(T)\right)^{\lambda_{3}}} \\
& -\frac{1}{\left(\frac{\lambda_{3}}{\left(\lambda_{3}-1\right)}\right)^{\lambda_{3}}\left(r-\alpha_{3}\right)^{\lambda_{3}}\left[\frac{C}{r}\left(e^{r T}-1\right)+\bar{C}\right]^{\lambda_{3}-1}}
\end{aligned}
$$


Consequently the option value is determined by:

$$
\begin{aligned}
F & =\tilde{B}_{3} \tilde{Y}_{3}^{\lambda_{3}} \\
& =\frac{1}{\left(r-\alpha_{3}\right)^{\lambda_{3}}} I_{3}(T)^{\left(1-\lambda_{3}\right)}\left[\left(\frac{\lambda_{3}}{\left(\lambda_{3}-1\right)}\right)^{1-\lambda_{3}}-\left(\frac{\left(\lambda_{3}-1\right)}{\lambda_{3}}\right)^{\lambda_{3}}\right] \tilde{Y}_{3}^{\lambda_{3}}
\end{aligned}
$$

\subsection{Appendix 2: Deriving $\mathrm{T}$ and Proof of Proposition 2}

a) Development of entry-level wages: Expected Path of Entry-level Wages: The development of the entry-level wages upon market entry is determined by

$$
d \tilde{Y}=\delta \tilde{Y}+\sigma \tilde{Y} d W
$$

We put $g(x)=\log x$ to get the Ito formula for $\log \tilde{Y}(t)$ :

$$
d(\log \tilde{Y}(t))=\left(\delta-\frac{1}{2} \sigma^{2}\right) d t+\sigma d W
$$

We obtain after integration

$$
\begin{aligned}
\log \tilde{Y}(T)-\log \tilde{Y}(0)= & \int_{0}^{T}\left(\delta-\frac{1}{2} \sigma^{2}\right) d t+\int_{0}^{T} \sigma d W \\
\Leftrightarrow & \log \tilde{Y}(T)=\log \tilde{Y}(0)+\left(\delta-\frac{1}{2} \sigma^{2}\right) T+\sigma W(T), \\
\tilde{Y}(T)= & \tilde{Y}(0) e^{\left(\left(\delta-\frac{1}{2} \sigma^{2}\right) T+\sigma W(T)\right)} \quad \text { and hence } \\
E \tilde{Y}(T)= & \tilde{Y}(0) e^{\delta T} . \\
& \frac{\partial E \tilde{Y}(T)}{\partial T}=\delta \tilde{Y}(0) e^{\delta T}
\end{aligned}
$$

and $\ln E \tilde{Y}(T)$ is a linear function in $T$ :

$$
\ln E \tilde{Y}(T)=\ln \tilde{Y}(0)+\delta T
$$

Expected First Time Realization of Entry-level Wages: We can determine the expected time $E\left(\tilde{T}_{i}\right)$ needed to reach a certain income level $\tilde{Y}_{i}$ for the first time given the present value $\tilde{Y}(0)$. By using the Girsanov theorem we can derive the probability density function of $\tilde{T}_{i}{ }^{23}$ given by

$$
f\left(\tilde{T}_{i}, \tilde{Y}(0), \tilde{Y}_{i}\right)=\frac{\ln \left(\frac{\tilde{Y}_{i}}{\tilde{Y}(0)}\right)}{\sqrt{2 \pi \sigma^{2}\left(\tilde{T}_{i}\right)^{3}}} e^{-\frac{\left(\ln \left(\frac{\tilde{Y}_{i}}{\tilde{Y}(0)}\right)-\left(\alpha-\frac{1}{2} \sigma^{2}\right) \tilde{T}_{i}\right)^{2}}{2 \sigma^{2} \tilde{T}_{i}}}
$$

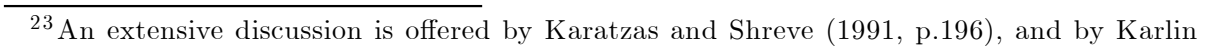
and Taylor (1975, p.363). 
with $\tilde{Y}_{i}>\tilde{Y}(0)$. With the Laplace transformation of $T^{24}$ :

$$
\begin{aligned}
E\left(e^{-\lambda \tilde{T}_{i}}\right) & =\int_{0}^{\infty} e^{-\lambda \tilde{T}_{i}} f\left(\tilde{T}_{i}\right) d \tilde{T}_{i} \\
& =e^{-\left[\sqrt{\left(\alpha-\frac{1}{2} \sigma^{2}\right)^{2}+2 \sigma^{2} \lambda}-\left(\alpha-\frac{1}{2} \sigma^{2}\right)\right] \frac{\ln \left(\frac{\tilde{Y}_{i}}{Y(0)}\right)}{\sigma^{2}}}
\end{aligned}
$$

we determine the expected time before market entry as

$$
\begin{aligned}
E\left(\tilde{T}_{i}\right) & =\int_{0}^{\infty} \tilde{T}_{i} f\left(\tilde{T}_{i}\right) d T \\
& =\frac{\ln \left(\frac{\tilde{Y}_{i}}{Y_{0}}\right)}{\delta-\frac{1}{2} \sigma^{2}}
\end{aligned}
$$

For each $\tilde{Y}_{i}$ we can determine each expected time $E\left(\tilde{T}_{i}\right)$ when this entrylevel wage $\tilde{Y}_{i}$ is reached for the first time. Hence for a continuous variation of $\tilde{Y}_{i}>\tilde{Y}(0), \tilde{Y}_{i} \in \mathbb{R}$ we can write $E(\tilde{T})$ as a function of any potential entry-level wage $\tilde{Y}$

$$
E(\tilde{T})=\frac{\ln \left(\frac{\tilde{Y}}{\tilde{Y}_{0}}\right)}{\delta-\frac{1}{2} \sigma^{2}} . \quad \text { see }(14) .
$$

Later we want to discuss the existence of the expected time $T^{*}$ of market entry for the threshold $Y^{*}(T)$ (first passage time for the threshold $Y^{*}$ (see 11)). Therefore, for each existing $E \tilde{T}=T$ we rewrite (14) as a cotinous function $f$ of time $T$

$$
\tilde{Y}=\tilde{Y}_{0} e^{T\left(\delta-\frac{1}{2} \sigma^{2}\right)}=: f(T) .
$$

$\ln f(T)$ is a linear function in $T$ :

$$
\ln f(T)=\ln \tilde{Y}_{0}+T\left(\delta-\frac{1}{2} \sigma^{2}\right) .
$$

\subsection{Appendix 3: Existence of a solution for the expected time $T^{*}$ of market entry, and determination of $T^{*}$ as an implicit function/Proof of Proposition 3:}

In general we look for the conditions described in figure 6 . The threshold starts above the entry-level wage curve. For positive $T$ the threshold will have an unique intersection with the expected first-time realization of the entry-level wage curve from below at $A$. Hence at the time of expected market entry denoted by $T^{*} G=Y^{*}(T)-f(T)=0$ and the $G$ curve has a negative slope $\frac{d G}{d T}<0$.

\footnotetext{
${ }^{24}$ See Ross (1996) proposition 8.4.1.
} 
(a)

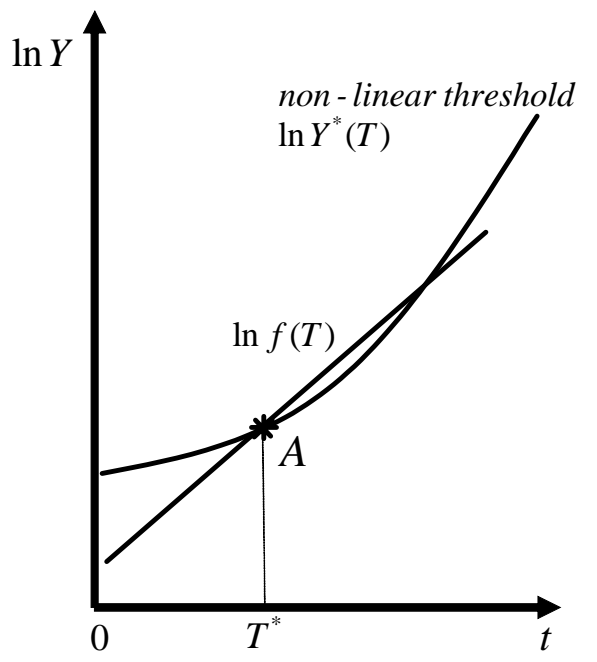

(b)

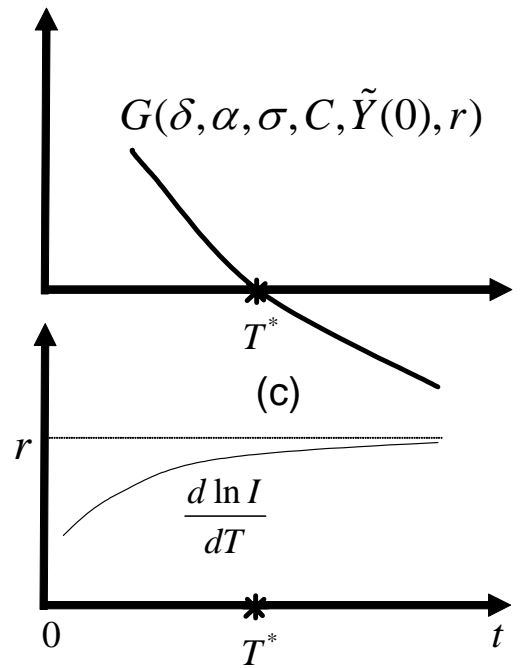

Figure 6: Intersection of the threshold and expected first-time realization of initial income value function, and distance function $\mathrm{G}$.

Further, at $T^{*}$ the threshold $Y^{*}(T=0)$ must start above $f(T)$, and $G>0$ during the pre-market entry period $\left(0<t<T^{*}\right)$. Otherwise the market entry would have taken place.

\subsubsection{Negative slope of $G$ :}

$$
\begin{aligned}
\frac{\partial G}{\partial T^{*}} & =\frac{\lambda}{\lambda-1}(r-\alpha) C e^{r T^{*}}-\tilde{Y}_{0} e^{T^{*}\left(\delta-\frac{1}{2} \sigma^{2}\right)}<0 \\
& \Leftrightarrow \frac{\lambda}{\lambda-1}(r-\alpha)\left[\frac{C}{r} e^{\left(r-\delta+\frac{1}{2} \sigma^{2}\right) T^{*}}-\left(\frac{C}{r}-\bar{C}\right) e^{\left(-\delta+\frac{1}{2} \sigma^{2}\right) T^{*}}\right]>\frac{\lambda}{\lambda-1} \frac{(r-\alpha)}{\delta-\frac{1}{2} \sigma^{2}} C e^{\left(r-\delta+\frac{1}{2} \sigma^{2}\right) T^{*}} \\
& \Leftrightarrow e^{-r T^{*}}>\frac{\frac{C}{\delta-\frac{1}{2} \sigma^{2}}-\frac{C}{r}}{-\frac{C}{r}+\bar{C}}
\end{aligned}
$$




$$
\begin{aligned}
& \Leftrightarrow-r T^{*}>\ln \left(\frac{\frac{C}{\delta-\frac{1}{2} \sigma^{2}}-\frac{C}{r}}{-\frac{C}{r}+\bar{C}}\right) \Leftrightarrow T^{*}<\frac{-1}{r} \ln \left(\frac{\frac{C}{\delta-\frac{1}{2} \sigma^{2}}-\frac{C}{r}}{-\frac{C}{r}+\bar{C}}\right) \\
\text { and } \frac{\frac{C}{\delta-\frac{1}{2} \sigma^{2}}-\frac{C}{r}}{-\frac{C}{r}+\bar{C}} & <1 \Leftrightarrow \frac{C}{\delta-\frac{1}{2} \sigma^{2}}-\frac{C}{r}<-\frac{C}{r}+\bar{C} \\
& \Leftrightarrow \frac{C}{\delta-\frac{1}{2} \sigma^{2}}<\bar{C} \Leftrightarrow C<\left(\delta-\frac{1}{2} \sigma^{2}\right) \bar{C}<r \bar{C} \quad \text { see } \quad 17
\end{aligned}
$$

Before market entry $f\left(T^{*}\right)$ must grow faster than the threshold curve. Only for a negative slope $G$ can approach and eventually reach zero. $\frac{\partial G}{\partial T}<0$ is fulfilled if condition $\bar{C}>\frac{C}{r}$ (condition 17)

\subsubsection{Existence of an intersect of $Y^{*}\left(T^{*}\right)$ and $f\left(T^{*}\right)$ for positive $T^{*}$ :}

a) As the function $\ln Y^{*}(T)$ is convex if condition (17) holds (see 24) and the function $\ln f(T)$ is linear, there are at most two intersections. We are interested only in intersections at $T>0$. An intersection for positive values of both functions exists if condition (16) and (17) holds and $G=0$ for positive values of $T^{*}$.

$$
\begin{aligned}
& G=Y^{*}\left(T^{*}\right)-f\left(T^{*}\right)=0 \\
& \Leftrightarrow \frac{\lambda}{\lambda-1}(r-\alpha)\left[\frac{C}{r}\left(e^{r T^{*}}-1\right)+\bar{C}\right]-\tilde{Y}(0) e^{\left(\delta-\frac{1}{2} \sigma^{2}\right) T^{*}}=0 \\
& \Leftrightarrow \frac{1}{\left(\delta-\frac{1}{2} \sigma^{2}\right)} \ln \left[\frac{\frac{\lambda}{\lambda-1}(r-\alpha)\left[\frac{C}{r}\left(e^{r T^{*}}-1\right)+\bar{C}\right]}{\tilde{Y}(0)}\right]=T^{*}>0 \\
& \Rightarrow \frac{\lambda}{\lambda-1}(r-\alpha)\left[\frac{C}{r}\left(e^{r T^{*}}-1\right)+\bar{C}\right]>\tilde{Y}(0) \\
& \Leftrightarrow T^{*}>\frac{1}{r} \ln [\underbrace{\frac{\lambda-1}{\Leftrightarrow}}_{<\frac{r}{\lambda} \frac{1}{(r-\alpha)} \frac{r}{C} \tilde{Y}(0)+1-\frac{r}{C} \bar{C}}] \text { see }(16) \\
& \Leftrightarrow \bar{C}>\frac{\lambda-1}{\lambda} \frac{1}{(r-\alpha)} \frac{r}{C} \tilde{Y}(0) \\
& \Leftrightarrow \bar{C}>\frac{\lambda-1}{\lambda} \frac{1}{(r-\alpha)} \tilde{Y}(0)
\end{aligned}
$$

The last inequality is a condition for the axis intercepts of $Y^{*}$ and $f(T)$. It guarantees that $f(T)$ has a lower value in $T=0$ than $Y^{*}$.

$$
\begin{aligned}
Y^{*}(0) & >f(0)=\tilde{Y}(0) \\
& \Rightarrow \bar{C}>\frac{\lambda-1}{\lambda} \frac{1}{(r-\alpha)} \tilde{Y}(0)
\end{aligned}
$$


b) Further, in figure 6 the condition for an intersection and a negative slope has to hold simultaneously at $T^{*}$. We need to show that there is a $T^{*}$ were both $\frac{d G}{d T}<0$ and $G=0$ hold. That is, we can find a minimum level for $\tilde{Y}(0)$ in order to ensure an intersection and a negative slope:

$$
\begin{aligned}
& \underbrace{\frac{1}{\left(\delta-\frac{1}{2} \sigma^{2}\right)} \ln \left[\frac{\frac{\lambda}{\lambda-1}(r-\alpha)\left[\frac{C}{r}\left(e^{r T^{*}}-1\right)+\bar{C}\right]}{\tilde{Y}(0)}\right]}_{\text {follows from } G=0}=T^{*}<\underbrace{\frac{-1}{r} \ln \left(\frac{\frac{C}{\delta-\frac{1}{2} \sigma^{2}}-\frac{C}{r}}{-\frac{C}{r}+\bar{C}}\right)}_{\text {follows from the slope condition }} \\
& \ln \left[\frac{\lambda}{\lambda-1}(r-\alpha)\left[\frac{C}{r}\left(e^{r T^{*}}-1\right)+\bar{C}\right]\right]+\underbrace{\frac{\left(\delta-\frac{1}{2} \sigma^{2}\right)}{r} \ln \left(\frac{\frac{C}{\delta-\frac{1}{2} \sigma^{2}}-\frac{C}{r}}{-\frac{C}{r}+\bar{C}}\right)}_{c<0}<\ln \tilde{Y}(0) \\
& {\left[\frac{\lambda}{\lambda-1}(r-\alpha)\left[\frac{C}{r}\left(e^{r T^{*}}-1\right)+\bar{C}\right]\right] e^{c}<\tilde{Y}(0)} \\
& \Rightarrow T^{*}<\frac{1}{r} \ln \left(\tilde{Y}(0) \frac{r}{C} \frac{1}{(r-\alpha)} \frac{\lambda-1}{\lambda} e^{-c}+1-\frac{r \bar{C}}{C}\right) \\
& \tilde{Y}(0) \frac{r}{C} \frac{1}{(r-\alpha)} \frac{\lambda-1}{\lambda} e^{-c}+1-\frac{r \bar{C}}{C}>1 \\
& \tilde{Y}(0)>\bar{C} \frac{\lambda}{\lambda-1}(r-\alpha) e^{c}
\end{aligned}
$$

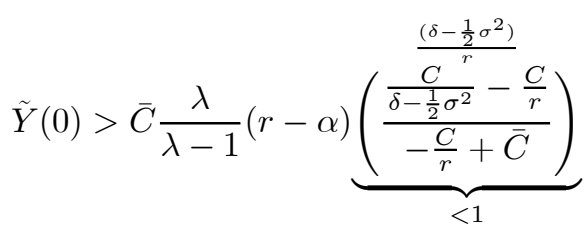

\subsection{3 c) $T^{*}$ as an implicit function of various variables/Proof of Propositon 3:}

Proof of Proposition 3: If

(i) condition (16) holds,

(ii) the derivative $\frac{\partial G}{\partial T}\left(\alpha, r, \sigma, T^{*}, C, \tilde{Y}(0), \delta, \bar{C}\right)$ is negative (see condition (??)) for each vector $\left(\alpha, r, \sigma, T^{*}, C, \tilde{Y}(0), \delta, \bar{C}\right)$ and

(iii) the partial derivatives of $G$ by of $\alpha, \sigma, C, \tilde{Y}(0), \delta, \bar{C}$ and $r$ are continuous (vide infra), we can apply the implicit function theorem. Hence for a marginal environment of any vector $\left(\alpha, r, \sigma, T^{*}, C, \tilde{Y}(0), \delta, \bar{C}\right), T^{*}$ is an implicit function of of $\alpha, \sigma, C, \tilde{Y}(0), \delta, \bar{C}$ and $r$. q.e.d. 


$$
T^{*}=T^{*}(\alpha, \sigma, C, \tilde{Y}(0), \delta, r, \bar{C})
$$

7.3.4 d) Curve properties of $V=V^{\text {gross }}-I$ (Net Current Value)

$$
\begin{array}{r}
V=\frac{\tilde{Y}(0) e^{\delta T}}{r-\alpha}-\frac{C}{r}\left(e^{r T}-1\right)-\bar{C} \\
\Rightarrow \quad\left(V^{\text {gross }}-I\right)(0)=\frac{\tilde{Y}(0)}{r-\alpha}-\bar{C} \\
\frac{d(V)}{d T}=\frac{\delta \tilde{Y}(0) e^{\delta T}}{r-\alpha}-C e^{r T}
\end{array}
$$

Maximum of the curve:

$$
\begin{gathered}
0=\frac{d(V)}{d T}=\frac{\delta \tilde{Y}(0) e^{\delta T}}{r-\alpha}-C e^{r T} \Rightarrow \ln \left[\frac{\delta \tilde{Y}(0)}{r-\alpha}\right]+\delta T=\ln C+r T \\
\Leftrightarrow T=\frac{1}{r-\delta} \ln \left[\frac{\tilde{Y}(0)}{r-\alpha} \frac{\delta}{C}\right] \\
\frac{d^{2}(V)}{d T^{2}}=\frac{\delta^{2} \tilde{Y}(0) e^{\delta T}}{r-\alpha}-r C e^{r T}<0 \\
\Leftrightarrow T>\frac{1}{r-\delta} \ln \left(\frac{\delta^{2} \tilde{Y}(0)}{r-\alpha} \frac{1}{r C}\right) \\
\text { for } \quad=\frac{1}{r-\delta} \ln \left[\frac{\tilde{Y}(0)}{r-\alpha} \frac{\delta}{C}\right] \text { we get } \\
\frac{\delta}{r} \\
>1 \\
\frac{\partial V}{\partial C}=-\frac{1}{r} e^{r T}<0
\end{gathered}
$$

\subsection{Appendix 4: Proof of Proposition 4}

To apply comparative statics for the implicit function $T^{*}=T^{*}(\alpha, \sigma, C, \tilde{Y}(0), \delta r)$ we need to consider

$$
\frac{\partial G}{\partial T}=\frac{\lambda}{\lambda-1}(r-\alpha) C e^{r T}-\left(\delta-\frac{1}{2} \sigma^{2}\right) \tilde{Y}(0) e^{\left(\delta-\frac{1}{2} \sigma^{2}\right) T} \gtreqless 0
$$

We are only interested in values of $T^{*}$, described by point $A$ in figure 6 ,conditions (16) and $\frac{\partial G}{\partial T^{*}}<0(17)$. Then at $T^{*}$ we obtain: 


$$
\begin{aligned}
& \frac{d T^{*}}{d \sigma}=-\frac{\frac{d G}{d \sigma}}{\frac{\partial G}{\partial T}}
\end{aligned}
$$

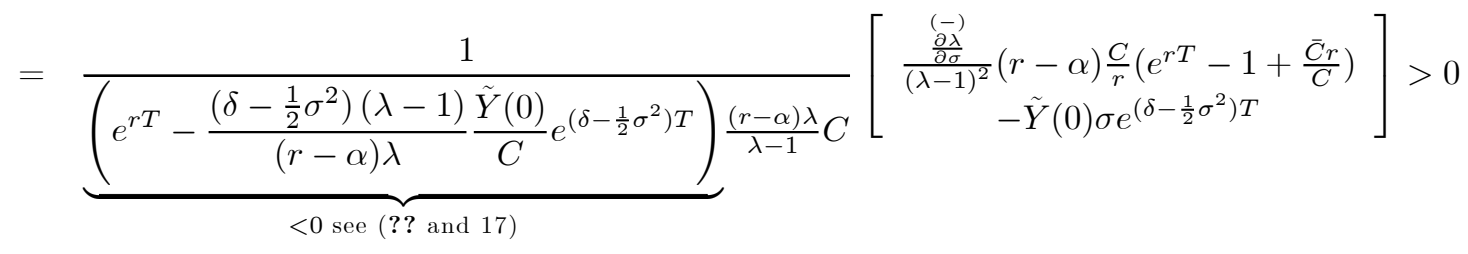

\subsection{Appendix 5: Proof of Proposition 5}

$$
\frac{d T^{*}}{d \alpha}=-\frac{\frac{d G}{d \alpha}}{\frac{\partial G}{\partial T}}=\underbrace{\frac{\left[e^{r T}-1+\frac{\bar{C} r}{C}\right]}{\left(e^{r T}-\frac{\left(\delta-\frac{1}{2} \sigma^{2}\right)(\lambda-1)}{(r-\alpha) \lambda} \frac{\tilde{Y}(0)}{C} e^{\left(\delta-\frac{1}{2} \sigma^{2}\right) T}\right)}}_{<0 \text { see (?? and 17) }} \frac{1}{(r-\alpha) r}<0
$$

\subsection{Appendix 6: Proof of Proposition 6}

$$
\frac{d T^{*}}{d \tilde{Y}(0)}=-\frac{\frac{d G}{d \tilde{Y}(0)}}{\frac{\partial G}{\partial T}}=\underbrace{\frac{1}{\lambda-1}(r-\alpha) C e^{\left(r-\delta+\frac{1}{2} \sigma^{2}\right) T}-\left(\delta-\frac{1}{2} \sigma^{2}\right) \tilde{Y}(0)}_{<0 \text { see }(? ? \text { and } 17)}<0
$$

\subsection{Appendix 7: Proof of Proposition 7}

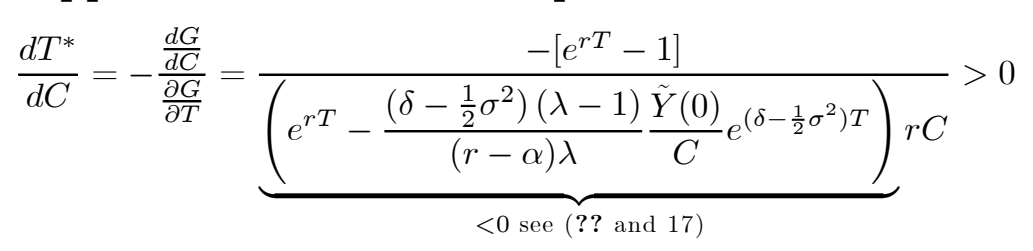

\subsection{Appendix 8: Proof of Proposition 8}

For the derivative with respect to $\delta$ and $r$ we need an approximation of $I(T)$ to examine the sign. We approximate $I(T)$ for the time range between 0 and the point $T^{*}$ by a log linear function with the parameter $\beta$ denoting the average growth rate of total accumulated costs between 0 and $T^{*}$. Economically, this simplification describes a approximation where total costs are payable only at the end of the education period. The non-log linear path of cost accumulation is proximated as a continous geometric growth process. Therefore we introduce a parameter $\beta$ that determines the average growth rate of $I(T)$. 


$$
\bar{C} e^{\beta T} \approx \frac{C}{r}\left(e^{r T}-1\right)+\bar{C}
$$

Note that we approximate a non-linear function $(I)$ with a non-linear growth rate through a log-linear function which has the same unique positive intersection with the logarithmized income threshold curve. We consider the shape of $\ln I(T)$, which is convex as shown in appendix 1, condition (24).

$$
\begin{aligned}
\frac{\partial \ln I}{\partial T} & =\frac{C e^{r T}}{\frac{C}{r}\left(e^{r T}-1\right)+\bar{C}}>0 \\
& =\frac{C e^{r T}(r \bar{C}-C)}{\left(\frac{C}{r}\left(e^{r T}-1\right)+\bar{C}\right)^{2}}>0 \quad \text { since (17) } \\
& =\lim _{T \rightarrow \infty} \frac{r e^{r T}}{\left[1+\frac{-1+\frac{r \bar{C}}{C}}{e^{r T}}\right] e^{r T}}=r
\end{aligned}
$$

and obviously

$$
\ln \left[\bar{C} e^{\beta T}\right]_{T=0}=\ln \bar{C}=\ln I(0) .
$$

As both curves intersect in $T=T^{*}$ we can determine a $\beta$ that satisfies the condition $\bar{C} e^{\beta T} \approx \frac{C}{r}\left(e^{r T}-1\right)+\bar{C}:$

$$
\begin{aligned}
\bar{C} e^{\beta T^{*}} & \approx \frac{C}{r}\left(e^{r T^{*}}-1\right)+\bar{C} \\
\beta & =\frac{\ln \left[\frac{C}{r C}\left(e^{r T^{*}}-1\right)+1\right]}{T^{*}}
\end{aligned}
$$

As $Y^{*}(0)>\tilde{Y}(0)$ and $\ln \left(\bar{C} e^{\beta T^{*}}\right)$ and $\ln I(T)$ start at the same point, the corresponding condition for the approximation to (??) is

$$
\delta-\frac{1}{2} \sigma^{2}-\beta>0
$$

Plugging the above approximation into the threshold we can explicitly determine $T^{*}$ :

$$
\begin{aligned}
\frac{\lambda}{\lambda-1}(r-\alpha) \bar{C} e^{\beta T^{*}}-\tilde{Y}(0) e^{\left(\delta-\frac{1}{2} \sigma^{2}\right) T^{*}} & =0 \\
& \Leftrightarrow T^{*}=\ln \left(\frac{\lambda-1}{\lambda} \frac{1}{r-\alpha} \frac{\tilde{Y}(0)}{\bar{C}}\right) \frac{1}{\beta-\delta+\frac{1}{2} \sigma^{2}} \\
& >0, \text { for } \frac{\lambda-1}{\lambda} \frac{1}{r-\alpha}<\frac{\bar{C}}{\tilde{Y}(0)} . \quad \text { see }(16)
\end{aligned}
$$




$$
\frac{d T^{*}}{d \delta}=\frac{1}{\left(\beta-\delta+\frac{1}{2} \sigma^{2}\right)^{2}} \overbrace{\ln \left(\frac{\lambda-1}{\lambda} \frac{1}{r-\alpha} \frac{\tilde{Y}(0)}{\bar{C}}\right)}^{<0 \text { see (16) }}+\frac{1}{\beta-\delta+\frac{1}{2} \sigma^{2}} \frac{1}{\lambda-1} \frac{\stackrel{\frac{\partial \lambda}{\partial \delta}}{\lambda}}{\frac{(-)}{\lambda}}>0
$$

Similar to the derivative of $T^{*}$ with respect to $r$ we have to examine under which condition which summand prevails. Here we assume that the effect of the option value is dominant.

\subsection{Appendix 9: Proof of Proposition 9}

$$
\begin{aligned}
\frac{d T^{*}}{d r} & =\frac{1}{\beta-\delta+\frac{1}{2} \sigma^{2}} \frac{\lambda}{\lambda-1}(r-\alpha) \frac{\bar{C}}{\tilde{Y}(0)}\left[\frac{\frac{\partial \lambda}{\partial r}}{\lambda^{2}} \frac{1}{r-\alpha} \frac{\tilde{Y}(0)}{\bar{C}}-\frac{\lambda-1}{\lambda} \frac{1}{(r-\alpha)^{2}} \frac{\tilde{Y}(0)}{\bar{C}}\right] \\
& =\underbrace{\frac{1}{\beta-\delta+\frac{1}{2} \sigma^{2}}}_{(-)}[\underbrace{\frac{\frac{(+)}{\partial r}}{\lambda(\lambda-1)}-\frac{1}{(r-\alpha)}}_{=: X}] \quad \text { for } \quad \beta-\delta+\frac{1}{2} \sigma^{2}<0
\end{aligned}
$$

To find out if $X \gtreqless 0$ we need to follow three steps:

1) Assume a sufficient condition for $X>0$ and $X<0$ : From our knowledge of the system we assume a sufficient condition for an unambigious sign. It is supposed that

$$
\begin{array}{ll}
\frac{3}{8} \sigma^{2}+\frac{3}{2} \delta>r & \text { implies } X>0 . \\
\frac{3}{8} \sigma^{2}+\frac{3}{2} \delta<r & \text { implies } X<0 .
\end{array}
$$

2) Show that conditions (26) and (27) hold: We now show that (26) and (27) are sufficient conditions for obtaining an unambiguous sign for $X$ :

a) From (26) we obtain $\lambda<3 / 2$ and from (27) we obtain $\lambda>$ $3 / 2$; the latter case will be in brackets: $[<]$

$$
\begin{aligned}
\frac{3}{4} \sigma^{2}+3 \delta & >[<] 2 r \\
\frac{3}{4}+2 \frac{\delta}{\sigma^{2}}+\frac{\delta^{2}}{\sigma^{4}} & >[<]-\frac{\delta}{\sigma^{2}}+\frac{\delta^{2}}{\sigma^{4}}+\frac{2 r}{\sigma^{2}} \\
1+2 \frac{\delta}{\sigma^{2}}+\left(\frac{\delta}{\sigma^{2}}\right)^{2} & >[<] \frac{1}{4}-\frac{\delta}{\sigma^{2}}+\frac{\delta^{2}}{\sigma^{4}}+\frac{2 r}{\sigma^{2}} \\
\left(1+\frac{\delta}{\sigma^{2}}\right)^{2} & >[<]\left[\left(\frac{1}{2}-\frac{\delta}{\sigma^{2}}\right)^{2}+\frac{2 r}{\sigma^{2}}\right]
\end{aligned}
$$




$$
\begin{aligned}
1+\frac{\delta}{\sigma^{2}} & >[<]\left[\left(\frac{1}{2}-\frac{\delta}{\sigma^{2}}\right)^{2}+\frac{2 r}{\sigma^{2}}\right]^{\frac{1}{2}} \\
\frac{3}{2} & >[<] \frac{1}{2}-\frac{\delta}{\sigma^{2}}+\left[\left(\frac{1}{2}-\frac{\delta}{\sigma^{2}}\right)^{2}+\frac{2 r}{\sigma^{2}}\right]^{\frac{1}{2}}
\end{aligned}
$$

As $\lambda=\frac{1}{2}-\frac{\delta}{\sigma^{2}}+\left[\left(\frac{1}{2}-\frac{\delta}{\sigma^{2}}\right)^{2}+\frac{2 r}{\sigma^{2}}\right]^{\frac{1}{2}}$ we proved that the value of $\lambda$ depends on conditions (26) and (27). Therefore we obtain

$$
\begin{array}{ll}
\frac{3}{2}>\lambda & \text { for } \frac{3}{4} \sigma^{2}+3 \delta>2 r \\
\frac{3}{2}<\lambda & \text { for } \frac{3}{4} \sigma^{2}+3 \delta<2 r
\end{array}
$$

b) Now we apply this condition to $\mathrm{X}$ :

$$
\begin{gathered}
X=\frac{\left[\left(\frac{1}{2}-\frac{\delta}{\sigma^{2}}\right)^{2}+\frac{2 r}{\sigma^{2}}\right]^{-\frac{1}{2}} \frac{1}{\sigma^{2}}}{\lambda(\lambda-1)}-\frac{1}{r-\alpha}>[<] 0 \\
\frac{\left[\left(\frac{1}{2}-\frac{\delta}{\sigma^{2}}\right)^{2}+\frac{2 r}{\sigma^{2}}\right]^{-\frac{1}{2}} \frac{1}{\sigma^{2}}}{\lambda(\lambda-1)}>[<] \frac{1}{r-\alpha} \\
\frac{(r-\alpha)}{\lambda(\lambda-1) \delta} \frac{\delta}{\sigma^{2}}-\frac{\delta}{\sigma^{2}}+\frac{1}{2}>[<] \frac{1}{2}-\frac{\delta}{\sigma^{2}}+\left[\left(\frac{1}{2}-\frac{\delta}{\sigma^{2}}\right)^{2}+\frac{2 r}{\sigma^{2}}\right]^{\frac{1}{2}} \\
{\left[\frac{(r-\alpha)}{\lambda(\lambda-1) \delta}-1\right] \frac{\delta}{\sigma^{2}}>[<] \lambda-\frac{1}{2}} \\
\frac{(r-\alpha)}{\lambda(\lambda-1) \delta}-1 \quad[<]\left(\lambda-\frac{1}{2}\right) \frac{\sigma^{2}}{\delta} \\
r \quad[<] \lambda(\lambda-1)\left[\left(\lambda-\frac{1}{2}\right) \sigma^{2}+\delta\right]+\alpha
\end{gathered}
$$

From conditions (29) and (28) we know $\frac{3}{2}>\lambda$ for $\frac{3}{4} \sigma^{2}+3 \delta>2 r \quad$ and $\frac{3}{2}<\lambda$ for $\frac{3}{4} \sigma^{2}+3 \delta<2 r \quad$. Therefore we can examine whether we find true conditions for $X>0, X<0$ using the highest/lowest value of $\lambda$.

$$
\begin{aligned}
& \frac{(r-\alpha)}{\delta}>(<) \frac{3}{2}\left(\frac{3}{2}-1\right)\left[\left(\frac{3}{2}-\frac{1}{2}\right) \frac{\sigma^{2}}{\delta}+1\right] \\
& (r-\alpha)>(<) \frac{3}{4}\left[\sigma^{2}+\delta\right]
\end{aligned}
$$


(i) Conditions for $X>0$ :

$$
\begin{gathered}
r>\frac{3}{4}\left[\sigma^{2}+\delta\right]+\alpha \\
\frac{3}{8} \sigma^{2}+\frac{3}{2} \delta>r \quad \text { see above } \\
\frac{3}{8} \sigma^{2}+\frac{3}{2} \delta>r>\frac{3}{4}\left[\sigma^{2}+\delta\right]+\alpha \\
\Delta r=\frac{3}{8} \sigma^{2}+\frac{3}{2} \delta-\frac{3}{4} \sigma^{2}-\frac{3}{4} \delta-\alpha>0 \\
\Delta r=-\frac{3}{8} \sigma^{2}+\frac{3}{4} \delta-\alpha>0 \\
3 \delta>\frac{3}{2} \sigma^{2}+4 \alpha \\
\delta>\frac{1}{2} \sigma^{2}+\frac{4}{3} \alpha
\end{gathered}
$$

(i) Conditions for $X<0$ :

$$
\begin{aligned}
& r<\frac{3}{4}\left[\sigma^{2}+\delta\right]+\alpha \\
& \frac{3}{8} \sigma^{2}+\frac{3}{2} \delta<r \text { see } \quad(26) \\
& \frac{3}{4}\left[\sigma^{2}+\delta\right]+\alpha>r>\frac{3}{8} \sigma^{2}+\frac{3}{2} \delta \\
& \Delta r=\frac{3}{4}\left[\sigma^{2}+\delta\right]+\alpha-\frac{3}{8} \sigma^{2}-\frac{3}{2} \delta>0 \\
& \Delta r=\frac{3}{8} \sigma^{2}-\frac{3}{4} \delta+\alpha>0 \\
& \delta<\frac{1}{2} \sigma^{2}+\frac{4}{3} \alpha
\end{aligned}
$$

As we can see, there is a feasible combination of $\delta, \sigma^{2}$, and $\alpha$ that satisfies this condition. The assumption that $X>0$ and $X<0$ is proven under the derived conditions (26) and (27). 


\section{CESifo Working Paper Series}

for full list see www.cesifo-group.org/wp

(address: Poschingerstr. 5, 81679 Munich, Germany, office@cesifo.de)

2761 Larry Karp, Sacrifice, Discounting and Climate Policy: Five Questions, August 2009

2762 Marianna Belloc and Samuel Bowles, International Trade, Factor Mobility and the Persistence of Cultural-Institutional Diversity, August 2009

2763 Charles Noussair and Fangfang Tan, Voting on Punishment Systems within a Heterogeneous Group, August 2009

2764 Birgit Bednar-Friedl and Karl Farmer, Internationally Coordinated Emission Permit Policies: An Option for Withdrawers from the Kyoto Protocol?, August 2009

2765 Pierre M. Picard and David E. Wildasin, Labor Market Pooling, Outsourcing and Labor Contracts, August 2009

2766 Stefan Voigt and Lorenz Blume, The Economic Effects of Federalism and Decentralization - A Cross-Country Assessment, August 2009

2767 David S. Jacks, Christopher M. Meissner and Dennis Novy, Trade Booms, Trade Busts, and Trade Costs, August 2009

2768 Mario Jametti and Thomas von Ungern-Sternberg, Hurricane Insurance in Florida, August 2009

2769 Alessandro Balestrino, Kind of Black: The Musicians' Labour Market in Italy, August 2009

2770 Yosr Abid Fourati and Cathal O’Donoghue, Eliciting Individual Preferences for Pension Reform, August 2009

2771 Christian Breuer and Chang Woon Nam, VAT on Intra-Community Trade and Bilateral Micro Revenue Clearing in the EU, August 2009

2772 Choudhry Tanveer Shehzad, Jakob De Haan and Bert Scholtens, Growth and Earnings Persistence in Banking Firms: A Dynamic Panel Investigation, August 2009

2773 Erdal Yalcin, Uncertain Productivity Growth and the Choice between FDI and Export, August 2009

2774 Klaus Abberger, Wolfgang Nierhaus and Shynar Shaikh, Findings of the Signal Approach for Financial Monitoring in Kazakhstan, September 2009

2775 Sascha O. Becker, Francesco Cinnirella and Ludger Woessmann, The Trade-off between Fertility and Education: Evidence from before the Demographic Transition, September 2009 
2776 Thomas Aronsson and Erkki Koskela, Optimal Income Taxation, Outsourcing and Policy Cooperation in a Dynamic Economy, September 2009

2777 Joel Slemrod, Old George Orwell Got it Backward: Some Thoughts on Behavioral Tax Economics, September 2009

2778 Cagri Seda Kumru and Athanasios C. Thanopoulos, Social Security Reform and Temptation, September 2009

2779 Alessandro Bucciol and Roel M. W. J. Beetsma, Inter- and Intra-generational Consequences of Pension Buffer Policy under Demographic, Financial and Economic Shocks, September 2009

2780 Eduardo Strube and Marcelo Resende, Complementarity of Innovation Policies in the Brazilian Industry: An Econometric Study, September 2009

2781 Henry Tulkens and Vincent van Steenberghe, "Mitigation, Adaptation, Suffering": In Search of the Right Mix in the Face of Climate Change, September 2009

2782 Maria L. Loureiro, Anna Sanz-de-Galdeano and Daniela Vuri, Smoking Habits: Like Father, Like Son, Like Mother, Like Daughter, September 2009

2783 Momi Dahan, Tehila Kogut and Moshe Shalem, Do Economic Policymakers Practice what they Preach? The Case of Pension Decisions, September 2009

2784 Eytan Sheshinski, Uncertain Longevity and Investment in Education, September 2009

2785 Nannette Lindenberg and Frank Westermann, How Strong is the Case for Dollarization in Costa Rica? A Note on the Business Cycle Comovements with the United States, September 2009

2786 Leif Danziger, Noncompliance and the Effects of the Minimum Wage on Hours and Welfare in Competitive Labor Markets, September 2009

2787 Gerlinde Fellner, Rupert Sausgruber and Christian Traxler, Testing Enforcement Strategies in the Field: Legal Threat, Moral Appeal and Social Information, September 2009

2788 Gabriel J. Felbermayr, Mario Larch and Wolfgang Lechthaler, Unemployment in an Interdependent World, September 2009

2789 Sebastian G. Kessing, Federalism and Accountability with Distorted Election Choices, September 2009

2790 Daniel Gros, Global Welfare Implications of Carbon Border Taxes, September 2009

2791 Louis N. Christofides, Michael Hoy and Ling Yang, The Gender Imbalance in Participation in Canadian Universities (1977-2005), September 2009

2792 Jan K. Brueckner and Robert W. Helsley, Sprawl and Blight, September 2009 
2793 Vidar Christiansen and Stephen Smith, Externality-correcting Taxes and Regulation, September 2009

2794 John Beirne, Guglielmo Maria Caporale, Marianne Schulze-Ghattas and Nicola Spagnolo, Global and Regional Spillovers in Emerging Stock Markets: A Multivariate GARCH-in-mean Analysis, September 2009

2795 Rüdiger Pethig and Frieder Kolleß, Asymmetric Capital-Tax Competition, Unemployment and Losses from Capital Market Integration, September 2009

2796 Ngo Van Long, Horst Raff and Frank Stähler, Innovation and Trade with Heterogeneous Firms, September 2009

2797 Margit Osterloh and Bruno S. Frey, Research Governance in Academia: Are there Alternatives to Academic Rankings?, September 2009

2798 Thiess Buettner and Clemens Fuest, The Role of the Corporate Income Tax as an Automatic Stabilizer, September 2009

2799 Annette Alstadsæter, Measuring the Consumption Value of Higher Education, September 2009

2800 Peter Friedrich, Chang Woon Nam and Janno Reiljan, Local Fiscal Equalization in Estonia: Is a Reform Necessary?, September 2009

2801 Evžen Kočenda and Jan Hanousek, State Ownership and Control in the Czech Republic, September 2009

2802 Michael Stimmelmayr, Wage Inequality in Germany: Disentangling Demand and Supply Effects, September 2009

2803 Biswa N. Bhattacharyay, Towards a Macroprudential Surveillance and Remedial Policy Formulation System for Monitoring Financial Crisis, September 2009

2804 Margarita Katsimi, Sarantis Kalyvitis and Thomas Moutos, "Unwarranted" Wage Changes and the Return on Capital, September 2009

2805 Christian Lessmann and Gunther Markwardt, Aid, Growth and Devolution, September 2009

2806 Bas Jacobs and Dirk Schindler, On the Desirability of Taxing Capital Income to Reduce Moral Hazard in Social Insurance, September 2009

2807 Hans Gersbach and Noemi Hummel, Climate Policy and Development, September 2009

2808 David E. Wildasin, Fiscal Competition for Imperfectly-Mobile Labor and Capital: A Comparative Dynamic Analysis, September 2009

2809 Johan Eyckmans and Cathrine Hagem, The European Union's Potential for Strategic Emissions Trading through Minimal Permit Sale Contracts, September 2009 
2810 Ruediger Bachmann and Christian Bayer, The Cross-section of Firms over the Business Cycle: New Facts and a DSGE Exploration, October 2009

2811 Slobodan Djajić and Michael S. Michael, Temporary Migration Policies and Welfare of the Host and Source Countries: A Game-Theoretic Approach, October 2009

2812 Devis Geron, Social Security Incidence under Uncertainty Assessing Italian Reforms, October 2009

2813 Max-Stephan Schulze and Nikolaus Wolf, Economic Nationalism and Economic Integration: The Austro-Hungarian Empire in the Late Nineteenth Century, October 2009

2814 Emilia Simeonova, Out of Sight, Out of Mind? The Impact of Natural Disasters on Pregnancy Outcomes, October 2009

2815 Dan Kovenock and Brian Roberson, Non-Partisan 'Get-Out-the-Vote' Efforts and Policy Outcomes, October 2009

2816 Sascha O. Becker, Erik Hornung and Ludger Woessmann, Catch Me If You Can: Education and Catch-up in the Industrial Revolution, October 2009

2817 Horst Raff and Nicolas Schmitt, Imports, Pass-Through, and the Structure of Retail Markets, October 2009

2818 Paul De Grauwe and Daniel Gros, A New Two-Pillar Strategy for the ECB, October 2009

2819 Guglielmo Maria Caporale, Thouraya Hadj Amor and Christophe Rault, International Financial Integration and Real Exchange Rate Long-Run Dynamics in Emerging Countries: Some Panel Evidence, October 2009

2820 Saša Žiković and Randall K. Filer, Hybrid Historical Simulation VaR and ES: Performance in Developed and Emerging Markets, October 2009

2821 Panu Poutvaara and Andreas Wagener, The Political Economy of Conscription, October 2009

2822 Steinar Holden and Åsa Rosén, Discrimination and Employment Protection, October 2009

2823 David G. Mayes, Banking Crisis Resolution Policy - Lessons from Recent Experience Which elements are needed for robust and efficient crisis resolution?, October 2009

2824 Christoph A. Schaltegger, Frank Somogyi and Jan-Egbert Sturm, Tax Competition and Income Sorting: Evidence from the Zurich Metropolitan Area, October 2009

2825 Natasa Bilkic, Thomas Gries and Margarethe Pilichowski, Stay in School or Start Working? - The Human Capital Investment Decision under Uncertainty and Irreversibility, October 2009 